\title{
Single-atom Pd-Ru pair on Pt surface for promoting hydrogen oxidation in alkaline media
}

\section{Longsheng Cao}

Material Science and Engineering Department, UMD https://orcid.org/0000-0002-2917-6523

\section{Fernando Soto}

Texas A\&M University

\section{Dan Li}

University of Maryland, College Park

\section{Tao Deng}

University of Maryland, College Park

\section{Enyuan $\mathrm{Hu}$}

Chemistry Division, Brookhaven National Laboratory https://orcid.org/0000-0002-1881-4534

\section{Nico Eidson}

University of Maryland, College Park

\section{Xiao-Qing Yang}

Brookhaven National Laboratory https://orcid.org/0000-0002-3625-3478

\section{Perla B Balbuena}

Texas A\&M University https://orcid.org/0000-0002-2358-3910

Chunsheng Wang ( $\nabla$ cswang@umd.edu )

University of Maryland, College Park https://orcid.org/0000-0002-8626-6381

\section{Article}

Keywords: hydrogen oxidation reaction, HOR, Pt nanocatalysts, single-atom Pd-Ru pair

Posted Date: August 4th, 2020

DOI: https://doi.org/10.21203/rs.3.rs-48639/v1

License: (c) (i) This work is licensed under a Creative Commons Attribution 4.0 International License.

Read Full License 


\title{
Single-atom Pd-Ru pair on Pt surface for promoting hydrogen oxidation in alkaline media
}

Longsheng $\mathrm{Cao}^{1 \dagger}$, Fernando A. Soto ${ }^{2 \dagger}$, Dan $\mathrm{Li}^{1}$, Tao Deng ${ }^{1}$, Enyuan $\mathrm{Hu}^{3}$, Nico Eidson ${ }^{1}$, Xiao-Qing Yang ${ }^{3}$, Perla B. Balbuena ${ }^{2,4^{*}}$, and Chunsheng Wang ${ }^{1,5^{*}}$

${ }^{1}$ Department of Chemical and Biomolecular Engineering, University of Maryland, College Park, MD 20742, USA

${ }^{2}$ Department of Chemical Engineering, Texas A\&M University, College Station, Texas 77843, USA

${ }^{3}$ Chemistry Division, Brookhaven National Laboratory, Upton, NY 11973, USA

${ }^{4}$ Department of Materials Science and Engineering, Texas A\&M University, College Station, Texas 77843, USA

${ }^{5}$ Department of Chemistry and Biochemistry, University of Maryland, College Park, MD 20742, USA

$\dagger$ These authors contributed equally: Longsheng Cao, Fernando A. Soto.

*e-mail: cswang@umd.edu; balbuena@tamu.edu

\begin{abstract}
The hydrogen oxidation reaction (HOR) in alkaline media is critical for the alkaline fuel cell and electrochemical ammonia compressor. The sluggishness of HOR in the alkaline electrolyte requires platinum nano-catalysts, which are scarce and expensive. Decorating Pt catalysts with transition metals can boost the area specific activity (SA) of Pt nano-catalysts, but it often reduces the electrochemical active surface area (ECSA), resulting in a limited enhancement in Pt mass activity (MA). Single-atom surface modification of Pt catalysts can significantly enhance the reaction kinetics of single molecule, but it is less effective for HOR process that involve multiple molecules, i.e. $\mathrm{H}_{2}$ and $\mathrm{OH}^{-}$. Here we use a single-atom Pd-Ru pair to boost the activity of Pt nanocatalysts without loss of surface-active sites. Using a mildly catalytic thermal pyrolysis approach, single-Pd and single-Ru atom pair are precisely decorated on Pt nanoparticle surfaces, which is confirmed by Extended X-Ray Absorption Fine Structure (EXAFS) analysis. Density functional theory (DFT) calculations and ab-initio molecular dynamics (AIMD) simulations show the preferred adsorption of single-atom $\mathrm{Pd}$ and $\mathrm{Ru}$ dopants over $\mathrm{Pd}$ and $\mathrm{Ru}$ clustering on $\mathrm{Pt}$ surfaces. The single-atom Pd-Ru pair decorated Pt (Pd-Ru@Pt) catalyst features tri-active sites including: hydrophilic Pd promoting activation of adsorbed hydrogen atoms $\left(\mathrm{H}_{\mathrm{ads}}\right)$ via the hydrogen spillover effect, oxyphilic Ru facilitating the adsorption of hydroxide molecules $\left(\mathrm{OH}_{\mathrm{ads}}\right)$, and highlycatalytic Pt facilitating water formation with increased availability of $\mathrm{H}_{\mathrm{ads}}$ and $\mathrm{OH}_{\mathrm{ads}}$. In addition, the dopant decoration also reduces the hydrogen binding energy due to the shift of the (d) band center relative to the Fermi Level. The tri-active Pd-Ru@Pt catalyst shows 15.9 times higher area specific activity (SA) and 17.5 times larger mass activity (MA) than the state-of-the-art nano-Pt catalyst for HOR, and 2 times higher MA than nano-Pt for the hydrogen evolution reaction (HER). The mass exchange current density of single-atom Pd-Ru@Pt/C for the HOR/HER was 6.0 times that of the Pt/C, corresponding to 9.7 times that of $\mathrm{Pd} @ \mathrm{Pt} / \mathrm{C}$ and 6.5 times that of $\mathrm{Ru} @ \mathrm{Pt} / \mathrm{C}$. The
\end{abstract}


superior HOR/HER performance of the tri-active site catalyst is also demonstrated in ammonia and hydrogen pumps for practical application.

\section{Introduction}

The sluggish kinetics of electrochemical hydrogen and oxygen redox reactions in alkaline electrolytes hinder the wide application of renewable energy conversion and storage devices ${ }^{1}$ that use alkaline fuel cells ${ }^{2,3}$ and electrochemical gas compressors ${ }^{4}$. State-of-the-art electrocatalysts for these electrochemical conversion systems are usually platinum group metal (PGM)-based nanoparticles. However, the high cost of the Pt-based electrocatalysts severely limits their widespread adoption. An effective method for reducing the cost is to substantially reduce the amount of Pt required by enhancing the catalytic activity per given mass of Pt; i.e. Pt mass activity (MA).

The MA depends on both the electrochemically active surface area (ECSA) and the specific activity (SA, normalized by surface area). The ECSA can be enhanced by tailoring the geometrical structure, including ultra-small nanostructure ${ }^{5}$ and core-shell nanostructure with Pt skin ${ }^{6}$. The SA can be increased by modifying or decorating the Pt nanoparticle surface. Surface modification or decoration of Pt catalysts has been used for boosting the hydrogen evolution reaction (HER) ${ }^{7,8}$ and the oxygen reduction reaction $(\mathrm{ORR})^{9,10}$. For instance, decorating the Pt nanostructure surface using $\mathrm{Ni}(\mathrm{OH})_{2}$ clusters $^{8}$ greatly boosts the SA for the HER in alkaline electrolytes. However, such modification also reduces the ESCA by $30-50 \%{ }^{8}$. For surface modification, it is extremely challenging to increase the SA without substantially sacrificing the ECSA, which is necessary for achieving a high MA in both half-cells and full-cells. It is also more challenging enhancing the hydrogen oxidation reaction (HOR) compared to the HER in alkaline electrolytes, and the HOR enhancement by surface modification of Pt-based catalysts has rarely been reported before.

To boost the $\mathrm{HOR}\left(\mathrm{H}_{2}+2 \mathrm{OH}^{-} \rightarrow 2 \mathrm{H}_{2} \mathrm{O}+2 \mathrm{e}^{-}\right)$on $\mathrm{Pt}$, adsorption and activation of a large amount of $\mathrm{OH}_{\mathrm{ads}}$ and $\mathrm{H}_{\mathrm{ads}}$ surrounding $\mathrm{Pt}$ atoms are critical, which can be realized by decorating with $\mathrm{Ru}$ and Pd on the Pt surface, respectively. On Ru- and Pd-decorated Pt nanoparticles, the Ru and Pd act as catalyst promoters to increase the availability of $\mathrm{OH}_{\mathrm{ads}}$ and $\mathrm{H}_{\mathrm{ads}}$ surrounding $\mathrm{Pt}$ atoms, respectively. (Fig. 1 and Supplementary Fig. 1) It is critical to reduce the decorating species' sizes to prevent surface $\mathrm{Pt}$ active sites from being blocked while producing as many activated $\mathrm{Pt}$ sites with adjacent $\mathrm{Ru}$ and $\mathrm{Pd}$ atoms as possible for improved SA for the HOR. The ultimate choice to achieve the highest MA is the use of single-atoms to decorate $\mathrm{Pt}$, which allows the smallest number of $\mathrm{Ru}$ and $\mathrm{Pd}$ species to activate the most Pt atoms while minimizing blocking of surface $\mathrm{Pt}$ sites. However, the decorating of single Ru and single Pd atoms on the Pt surface has not been realized to date due to the limitation of current synthetic approaches.

Here, we create paired single-atom Pd-Ru doped Pt nanoparticles (single-atom Pd-Ru@Pt) with a high MA (both a high SA and a large ECSA) and a long durability. Importantly, the single-atom Pd-Ru@Pt substantially increases SA to $9.98 \mathrm{~mA} \mathrm{~cm}^{-2}$ and MA to $4.93 \mathrm{~A} \mathrm{mg}^{-1}$ metal for the HOR at 
$-50 \mathrm{mV}$ vs. reversible hydrogen electrode (RHE) at $\mathrm{pH} \mathrm{13,} \mathrm{which} \mathrm{are} 15.9$ and 17.5 times higher than those of the state-of-the-art $\mathrm{Pt} / \mathrm{C}$, respectively. To the best of our knowledge, such a high MA for the HOR in alkaline solution has not been achieved by any other nanomaterials under comparable conditions. The single-atom Pd-Ru@Pt catalyst also promotes the HER. The tri-active reaction mechanism for single-atom $\mathrm{Pd}$ and $\mathrm{Ru}$ decorated $\mathrm{Pt}$ is validated by extended $\mathrm{X}$-ray absorption fine structure (EXAFS) characterization, density functional theory (DFT) calculations, and ab-initio molecular dynamics (AIMD) simulations.

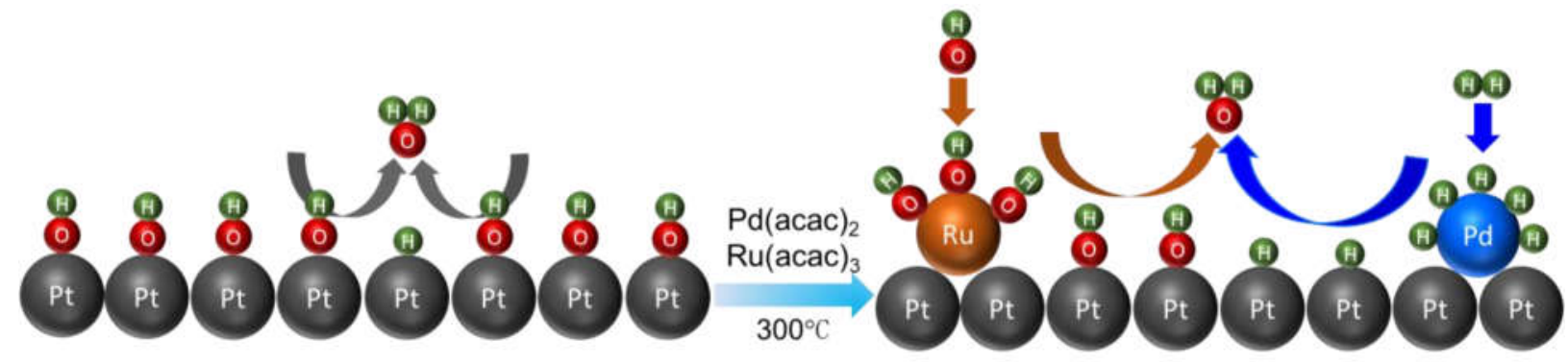

Fig. 1| Hydrogen oxidation reaction schematic diagram on Pt and single-atom Pd-Ru@Pt surface. The decoration of Pt nanoparticles with paired single-atom Pd-Ru species increases the availability of $\mathrm{H}_{\text {ads }}$ and $\mathrm{OH}_{\text {ads }}$ on the Pt surface to boost the specific catalytic activity for the HOR without sacrificing the ECSA.

\section{Results and discussion}

\section{Synthesis and geometric structure}

Inspired by the recent finding that nitrogen-rich carbon defect trapping $\mathrm{Cu}\left(\mathrm{NH}_{3}\right)_{\mathrm{x}}{ }^{11}$ can be used to prepare a single $\mathrm{Cu}$ atom catalyst, we used a vacuum assisted solid-phase synthetic approach to decorate single-atom Pd-Ru on Pt nanoparticle surfaces. As shown in Fig. 2a, we put carbon supported $\mathrm{Pt}$ nanoparticles $(\mathrm{Pt} / \mathrm{C})$ on a silicon wafer, loaded $\mathrm{Ru}(\mathrm{acac})_{3}$ and $\mathrm{Pd}(\mathrm{acac})_{2}$ in a combustion boat, and transferred them into a vacuumed glass tube. The $\operatorname{Ru}(\mathrm{acac})_{3}$ and $\mathrm{Pd}(\mathrm{acac})_{2}$ were chosen as $\mathrm{Pd}$ and $\mathrm{Ru}$ precursors because of their low evaporation temperatures. The glass tube was heated to $300^{\circ} \mathrm{C}$ for $3.0 \mathrm{~h}$. The vaporized $\mathrm{Pd}$ and Ru precursors were trapped by the surface defects of the Pt nanoparticles at high temperatures, generating the isolated $\mathrm{Pd}$ and $\mathrm{Ru}$ single atoms on the Pt surface via a catalytic pyrolysis effect of Pt forming single-atom Pd-Ru@Pt/C. As reference catalysts, atomic Pd doped Pt/C (Pd@Pt/C) and atomic Ru doped Pt/C ( $\mathrm{Ru} @ \mathrm{Pt} / \mathrm{C})$ were also synthesized using the same method.

X-ray power diffraction (XRD) of single-atom Pd-Ru decorated Pt showed only Pt peaks (Fig. 2b), indicating that decorated $\mathrm{Pd}$ and $\mathrm{Ru}$ atoms did not accumulate into $\mathrm{Pd}, \mathrm{Ru}$, or alloy phases. The morphology of single-atom Pd-Ru@Pt was characterized using transmission electron microscopy (TEM). As shown in Supplementary Fig. 2, the single-atom Pd-Ru@Pt catalysts with an average particle size of $2.9 \pm 0.4 \mathrm{~nm}$ dispersed uniformly on carbon support. Comparing the average particle size of Pd-Ru@Pt with that of the original Pt nanoparticle $(2.6 \pm 0.3 \mathrm{~nm})$ (Supplementary Fig. 3), the surface decoration thickness was $\sim 0.3 \mathrm{~nm}$, corresponding to a particle 
coating of one atomic layer. For the reference catalysts, the Pd@Pt/C (Supplementary Fig. 4) and $\mathrm{Ru} @ \mathrm{Pt} / \mathrm{C}$ (Supplementary Fig. 5) showed good dispersion and crystal structure, with average particle sizes of $3.2 \pm 0.5$ and $3.7 \pm 0.6$, respectively.

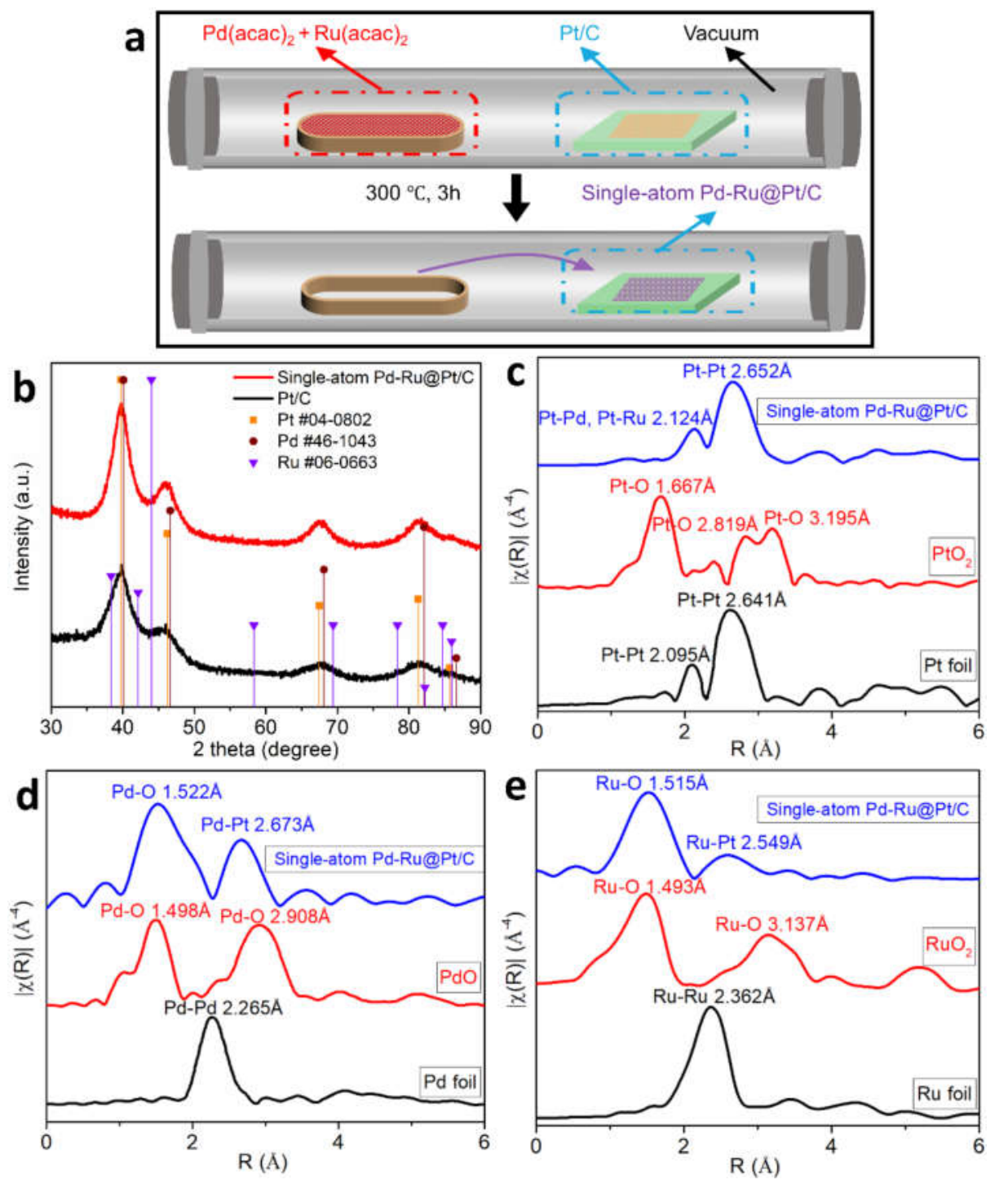

Fig. 2| Preparation and structure characterization of electrocatalysts. (a) Scheme for synthesizing single-atom Pd-Ru@Pt through a chemical vapor deposition (CVD) setup. (b) X-ray diffraction (XRD) pattern of single-atom Pd-Ru@Pt/C and Pt/C. (c) Pt, (d) Pd and (e) Ru Extended X-Ray Absorption Fine Structure (EXAFS) fitting results of single-atom Pd-Ru@Pt/C.

Single-atom Pd and $\mathrm{Ru}$ decoration on $\mathrm{Pt}$ for $\mathrm{Pd}-\mathrm{Ru} @ \mathrm{Pt} / \mathrm{C}$ catalysts was directly evidenced by extended X-ray absorption fine structure (EXAFS). The Pt EXAFS in Pd-Ru@Pt/C (Fig. 2c) displays a main peak at $\sim 2.652 \AA$, which is close to that of the Pt-Pt bond length in bulk Pt (2.641 $\AA \AA$ in Pt foil). Pt-Pd and Pt-Ru bonds at $2.124 \AA$ are also observed in the EXAFS. However, no sign of Pd-Pd bond (2.265 $\AA$ ) is observed in the Pd EXAFS (Fig. 2d) for the Pd-Ru@Pt/C catalyst. Additionally, a Pd-O peak at $\sim 1.522 \AA$ and a Pd-Pt peak at $\sim 2.673 \AA$ are observed. Similarly, no 
Ru-Ru bond (2.362 $\AA$ ) shows up in the Ru EXAFS (Fig. 2e), but a Ru-Pt peak at $\sim 2.549 \AA$ is featured. The first peak at $1.493 \AA$ in the Ru EXAFS corresponds to the Ru-O bond. The observed $\mathrm{Pd}-\mathrm{O}$ and Ru-O without Pt-O is consistent with a structure of single-atom Pd-Ru decoration on the Pt surface. Therefore, the EXAFS characterization confirmed the single-atom Pd-Ru doped Pt structure without the formation of $\mathrm{Pd}$ or $\mathrm{Ru}$ nanoparticles/clusters.

To further investigate the composition, the single-atom $\mathrm{Pd}-\mathrm{Ru} @ \mathrm{Pt} / \mathrm{C}$ catalyst was characterized using an energy-dispersive x-ray (EDX) spectroscopy elemental analysis and X-ray photoelectron spectroscopy (XPS). The EDX analysis shows that the atomic ratio of $\mathrm{Pt}: \mathrm{Pd}: \mathrm{Ru}$ is 1.0:0.3:0.3 in bulk (Supplementary Table 1), while the XPS gives an atomic ratio of 1.0:0.5:1.4 in the topmost layer (Supplementary Fig. 6-9, and Supplementary Table 2). The significant surface enrichment of both Pd and Ru confirms the surface doping on Pt surface, indicating that most Pd and Ru atoms are close together on top of the Pt surface.

Structure thermodynamic stability
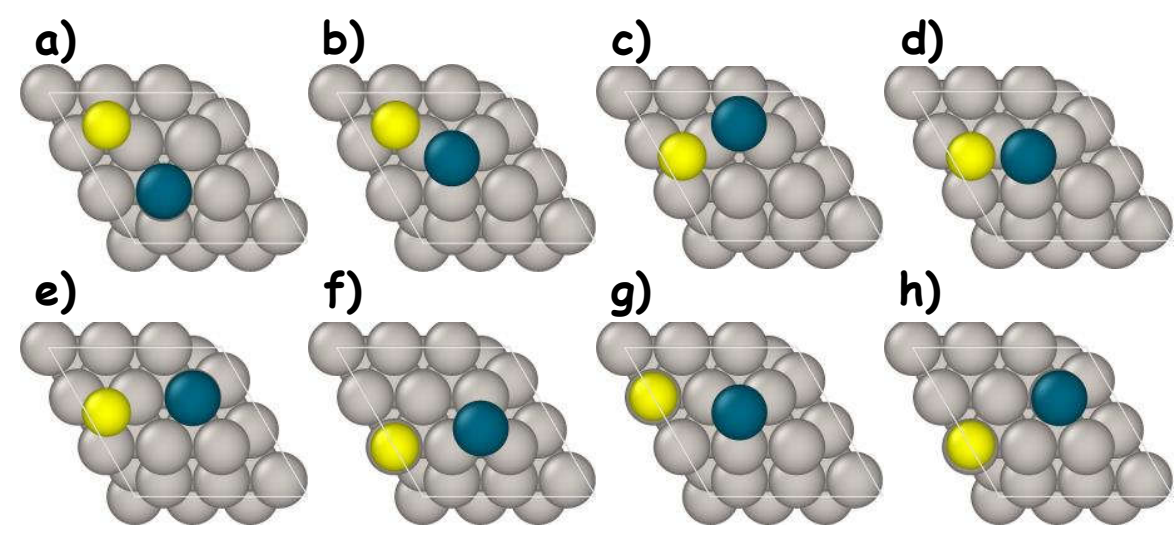

Fig. 3| Top view of the configurations simulated for Pd (dark green) and Ru (yellow) deposition on top of a Pt (111) surface (gray). Ru adsorbed at the hcp site and Pd adsorbed at the top site (a), Ru adsorbed at the hcp site and Pd adsorbed at the fcc site (b), Ru adsorbed at the fcc site and Pd adsorbed at the hcp site (c), Ru adsorbed at the fcc site and Pd adsorbed at the fcc site (d), Ru adsorbed at the fcc site and Pd adsorbed at the top site (e), Ru adsorbed at the top site and Pd adsorbed at the hcp site (f), Ru adsorbed at the top site and Pd adsorbed at the fcc site (g) and $\mathrm{Ru}$ adsorbed at the top site and $\mathrm{Pd}$ adsorbed at the top site $(\mathbf{h})$.

In order to gain an atomic-level understanding of the dopant decoration, the preferred adsorption sites of the Pd and $\mathrm{Ru}$ atoms at the fcc, hcp, and top sites of the Pt (111) surface were analyzed from a thermodynamic standpoint using DFT calculations (Fig. 3a-h). The analysis was restricted to the adsorption of dopants in detriment of the absorption process. The ground state energy geometry found under vacuum conditions predicted that the optimized site for both Pd and $\mathrm{Ru}$ adsorption on top of the Pt (111) slab is the fcc site (Fig. 3d). This configuration is at least 0.4 $\mathrm{eV}$ more thermodynamically stable than the least preferred configuration of $\mathrm{Ru}$ adsorbing at a hollow fcc site and Pd adsorbing at a top site (Fig. 3e). 
To explore whether the single Pd or single Ru atom prefers to deposit on the Pt (111) slab as a single-atom dopant or as a clustered dopant, we calculated the binding energy of a single-atom Pd (or $\mathrm{Ru}$ ) dopant on the Pt (111) surface and the energy required to add a dopant once a single-atom $\mathrm{Pd}$ (or $\mathrm{Ru}$ ) dopant was already adsorbed at an fcc site of the Pt (111) surface. The binding energy (E $\left.E_{\text {binding }}\right)$ per atom $(n)$ was calculated as the difference between the total energy of the optimized substrate-adsorbate and the sum of the relaxed clean surface ( $\left.\mathrm{E}_{\text {slab }}\right)$ and isolated dopants $\left(\mathrm{E}_{\mathrm{TM}}\right)$.

$\mathrm{E}_{\text {binding }}=\frac{\mathrm{E}_{\text {total }}-\left(\mathrm{E}_{\text {slab }}+\Sigma \mathrm{n} \mathrm{E}_{\text {тм }}\right)}{\mathrm{n}}$

Eq. 1

Upon optimization of the single-atom $\mathrm{Pd}$ (or Ru) adsorption on the Pt (111) surface, the binding energy of Pd-Pt $(-2.77 \mathrm{eV})$ is larger than either of the Pd-Pd $(-0.54 \mathrm{eV})$ and $\mathrm{Pd}-\mathrm{Ru}(-1.07 \mathrm{eV})$ binding energy. Also, the binding energy of Ru-Pt $(-5.47 \mathrm{eV})$ is also larger than either of the Ru$\mathrm{Ru}(-2.80 \mathrm{eV})$ and $\mathrm{Ru}-\mathrm{Pd}(-1.07 \mathrm{eV})$ binding energies. Therefore, both transition metals, Pd and $\mathrm{Ru}$, prefer to form bonds with Pt atoms at the fcc site of the Pt (111) surface rather than forming clusters.

To further investigate the long-term single-atom Pd-Ru@Pt stability, the energetic cost of sequential dopant addition (assuming a Ru or Pd is already adsorbed at an Pt fcc site) was simulated. The energy required to add a $\mathrm{Ru}$ atom and form a $\mathrm{Ru}-\mathrm{Ru}$ on the $\mathrm{Pt}$ surface is $1.30 \mathrm{eV} / \mathrm{atom}$. The energy required to add a $\mathrm{Pd}$ atom and form a $\mathrm{Pd}-\mathrm{Pd}$ on the $\mathrm{Pt}$ surface is $0.33 \mathrm{eV} /$ atom. Meanwhile, the energy required to add a $\mathrm{Pd}$ atom and form a single-atom $\mathrm{Ru}$ and $\mathrm{Pd}$ dopants adsorbed at the $\mathrm{Pt}$ (111) surface is $0.09 \mathrm{eV} / \mathrm{atom}$. Therefore, a single-atom Pd-Ru on the Pt surface is preferred over the clustering of Ru and Pd. In other words, using a single-atom Pd-Ru@Pt as a baseline, the agglomeration energy barriers of $\mathrm{Pd}$ and/or $\mathrm{Ru}$ on a Pt surface further stabilize the single-atom decoration system.
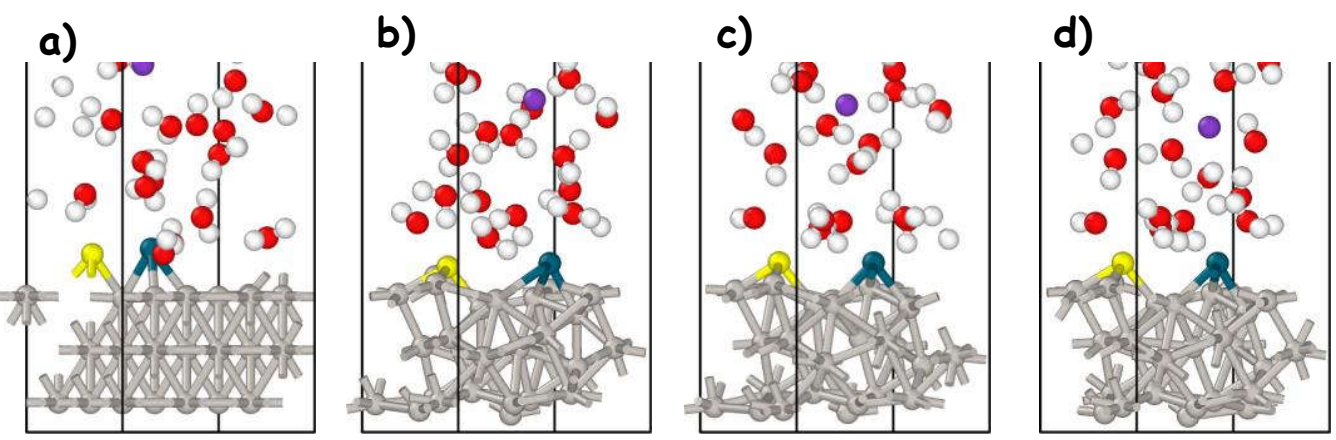

Fig. 4| Snapshots of the time evolution of the Pd-Ru@Pt (111) slab shown at a) the initial configuration, b) 6,000 fs, c) 12,000 fs and d) 18,000 fs. Color code: Gray, green, yellow, white, red, and purple spheres represent $\mathrm{Pt}, \mathrm{Pd}, \mathrm{Ru}, \mathrm{H}, \mathrm{O}$, and $\mathrm{K}$, respectively.

The thermodynamic stability of the Pd-Ru@Pt catalyst in an alkaline environment was investigated using AIMD simulations by an electrified $\mathrm{Pt}(111) / \mathrm{H}_{2} \mathrm{O}$ interface. As shown in Fig. 4, the Pd and Ru atoms continue to be adsorbed on the outermost surface of the Pt (111) catalyst with an elongated separation between the $\mathrm{Pd}$ and $\mathrm{Ru}$ atoms with respect to the initially optimized positions of $\sim 2.6 \AA$. Indeed, AIMD simulations in an NVT ensemble at room temperature (constant 
number of atoms, fixed volume, and controlled temperature) show that after approximately 18,000 fs of simulation time the Ru-Pd distance is close to $5 \AA$, confirming the single-atom pair stabililty in alkaline electrolyte.

\section{Electronic structure}
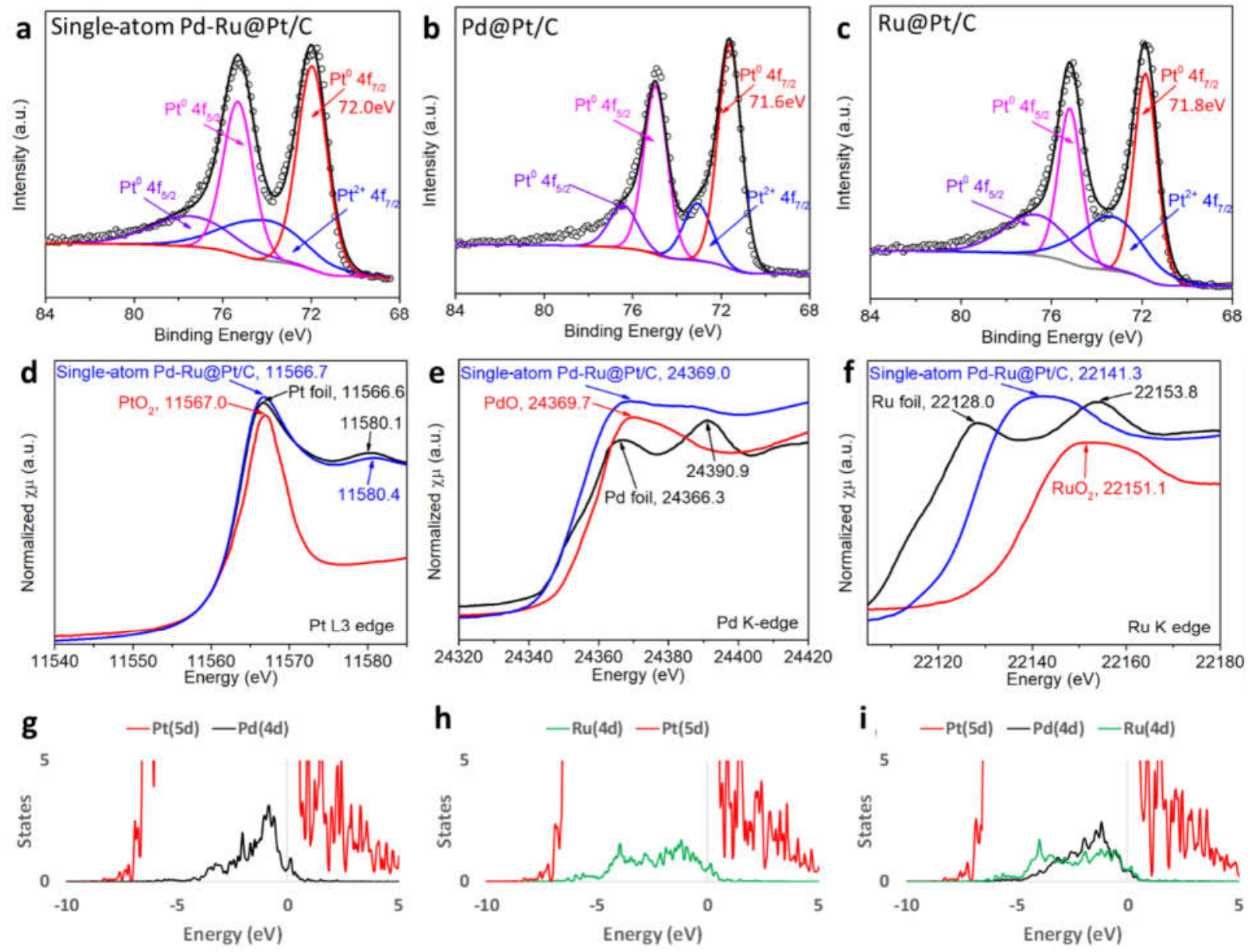

Fig. 5| Electronic structure characterization. XPS pattern of $\mathrm{Pt} 4 \mathrm{f}$ for (a) single-atom $\mathrm{Pd}-$ $\mathrm{Ru} @ \mathrm{Pt} / \mathrm{C},(\mathbf{b}) \mathrm{Pd} @ \mathrm{Pt} / \mathrm{C}$, and (c) Ru@Pt/C. (d) Pt L3-edge, (e) Pd K-edge, and (f) Ru K edge Xray Absorption Near Edge Structure (XANES) spectra. XANES of metallic Pt and $\mathrm{PtO}_{2}$ are shown in (d) as references ${ }^{12}$. XANES of metallic Pd and PdO are shown in (e) as references ${ }^{13}$. XANES of metallic $\mathrm{Ru}$ and $\mathrm{RuO}_{2}$ are shown in (f) as references ${ }^{14}$. Partial density of states (PDOS) for (g) Pd-doped system, (h) Ru-doped system, and (i) single-atom Pd-Ru@Pt (111) slab.

An XPS experiment was used to study the electronic effect of the dopant on Pt. The $\mathrm{Pt}^{0}: \mathrm{Pt}^{2+}$ ratio of $\mathrm{Pd}-\mathrm{Ru} @ \mathrm{Pt} / \mathrm{C}$ (4.1:1.0) from deconvoluted high-resolution $\mathrm{Pt} \mathrm{XPS}$ spectra was considerably larger than either of $\mathrm{Pd} @ \mathrm{Pt} / \mathrm{C}(3.3: 1.0)$ and $\mathrm{Ru} @ \mathrm{Pt} / \mathrm{C}(1.4: 1.0) \mathrm{Pt}^{0}: \mathrm{Pt}^{2+}$ ratio (Fig. 5c and Supplementary Table 3), which favors reactant activation on $\mathrm{Pd}-\mathrm{Ru} @ \mathrm{Pt} / \mathrm{C}$. The higher $\mathrm{Pt}^{0}$ binding energy in Pd-Ru@Pt/C (72.0 eV) (Fig. 5a) than that in Pt/C (71.8 eV) (Supplementary Fig. 7a and Supplementary Table 3) enhances the HOR kinetics by the weakening hydrogen 
adsorption on the surface. ${ }^{5}$ In contrast, the $\mathrm{Pt}^{0}$ binding energy in $\mathrm{Pd} @ \mathrm{Pt} / \mathrm{C}$ negatively shifts to 71.6 $\mathrm{eV}$ (Fig. 5b) from $71.8 \mathrm{eV}$ in Pt/C. The Ru-doping on Pt/C (Fig. 5c) does not change the $\mathrm{Pt}^{0}$ binding energy significantly, ruling out the electronic effect of Ru on the HOR performance for $\mathrm{Ru} @ \mathrm{Pt} / \mathrm{C}$.

Furthermore, the oxidation states of $\mathrm{Pt}, \mathrm{Pd}$, and $\mathrm{Ru}$, were probed by the white line intensity in the XANES spectra. The Pt L3-edge white line intensity of Pd-Ru@Pt/C is close to that of Pt foil (Fig. 5d), indicating that the average oxidation state of $\mathrm{Pt}$ is primarily zero. However, the white line intensity of the Pd K-edge (Fig. 5e) from Pd-Ru@Pt/C features a combination of metallic Pd and PdO. For the Ru K edge (Fig. 5f), the energy absorption edge fell between those of metallic $\mathrm{Ru}$ foil and $\mathrm{RuO}_{2}$, suggesting the co-existence of metallic and oxidized states.

In addition, the electronic structure signatures of the bare Pt (111) surface for Pd@Pt, Ru@Pt, and Pd-Ru@Pt were calculated using DFT. Fig. 5g shows that a valence band with additional occupied $(d)$ states was detected for the Pd@Pt (111) surface model, these $(d)$ states for Pd covers the higher region of the valence band, which extends from $\sim-3.6 \mathrm{eV}$ up to the Fermi level (set at 0 eV). Similarly, more (d) states were found (Fig. 5h) at the Fermi level of the Ru@Pt (111) surface when compared to the pristine $\mathrm{Pt}$ (111) surface. Interestingly, Ru provides more $(d)$ states deeper into the valence band while still contributing states closer to the Fermi level (Fig. 5i). Moreover, downshift of the $(d)$ band center reduces the filling of anti-bonding states resulting in a weaker adsorbate-surface bond and hence beneficial impact on improving the HOR kinetics of Pt in alkaline media ${ }^{5,15}$. Based on DFT, the (d) band center down shifts from $-2.01 \mathrm{eV}$ on the pristine Pt (111) surface to $-2.09 \mathrm{eV}$ on the $\mathrm{Ru} @ \operatorname{Pt}$ (111) surface, to $-2.16 \mathrm{eV}$ on the Pd@Pt (111), and to $-2.23 \mathrm{eV}$ on the Pd-Ru@Pt (111) surface. The Pd-Ru@Pt (111) surface shows the greatest downward shift in the Pt (d) band center, corresponding to the weakest hydrogen adsorption strength on the surface, i.e. the smallest hydrogen binding energy (HBE) and the most favorable HOR performance.

\section{Electrochemical performance}

The effects of surface decoration on electrocatalytic behavior in electrolytes with different $\mathrm{pH}$ was explored using a rotating disk electrode (RDE) test in both $0.1 \mathrm{M} \mathrm{KOH}$ and $0.1 \mathrm{M} \mathrm{HClO}_{4}$. Supplementary Fig. 9a confirms that the decreased HOR activities of Pt in alkaline electrolytes compared to that in acidic electrolytes is due to the increased HBE as evidenced by the $145 \mathrm{mV}$ positive shift of the hydrogen desorption peak in the cyclic voltammogram $(\mathrm{CV})^{16}$. After the single-atom Pd-Ru co-doping on the Pt surface, the hydrogen desorption peak of the Pd-Ru@Pt/C in the alkaline electrolyte shifted negatively to $116 \mathrm{mV}$ from $280 \mathrm{mV}$ for the Pt/C (Supplementary Fig. 9a-b), which is even comparable to that of the $\mathrm{Pd}-\mathrm{Ru} @ \mathrm{Pt} / \mathrm{C}$ in acidic electrolytes (Supplementary Fig. 9b). In contrast, only Pd or Ru doping on a Pt surface does not shift the peak-current potential of Pt significantly in alkaline electrolytes (Supplementary Fig. 9a, c-d). In $0.1 \mathrm{M} \mathrm{KOH}$, the single-atom Pd-Ru co-doping on Pt negatively shifted the desorption peak potential indicating the weakened dissociated $\mathrm{H}_{\mathrm{ads}}$ compared with the reference Pt/C (Fig. 6a), 
which contributed to HOR performance improvement. The DFT calculations confirm that the Pd and $\mathrm{Ru}$ co-doping on Pt reduces the HBE to $-0.42 \mathrm{eV}$, which is smaller than the HBE $(-0.59 \mathrm{eV})$ of Pd-doped Pt catalysts. The optimization process snapshots of the single-atom Pd-Ru@Pt (Supplementary Fig. 10) shows that an $\mathrm{H}$ atom that originally adsorbs on top of the $\mathrm{Pd}$ atom moves to the Pt surface, validating efficient hydrogen spillover when using Pd in the presence of Ru dopants.
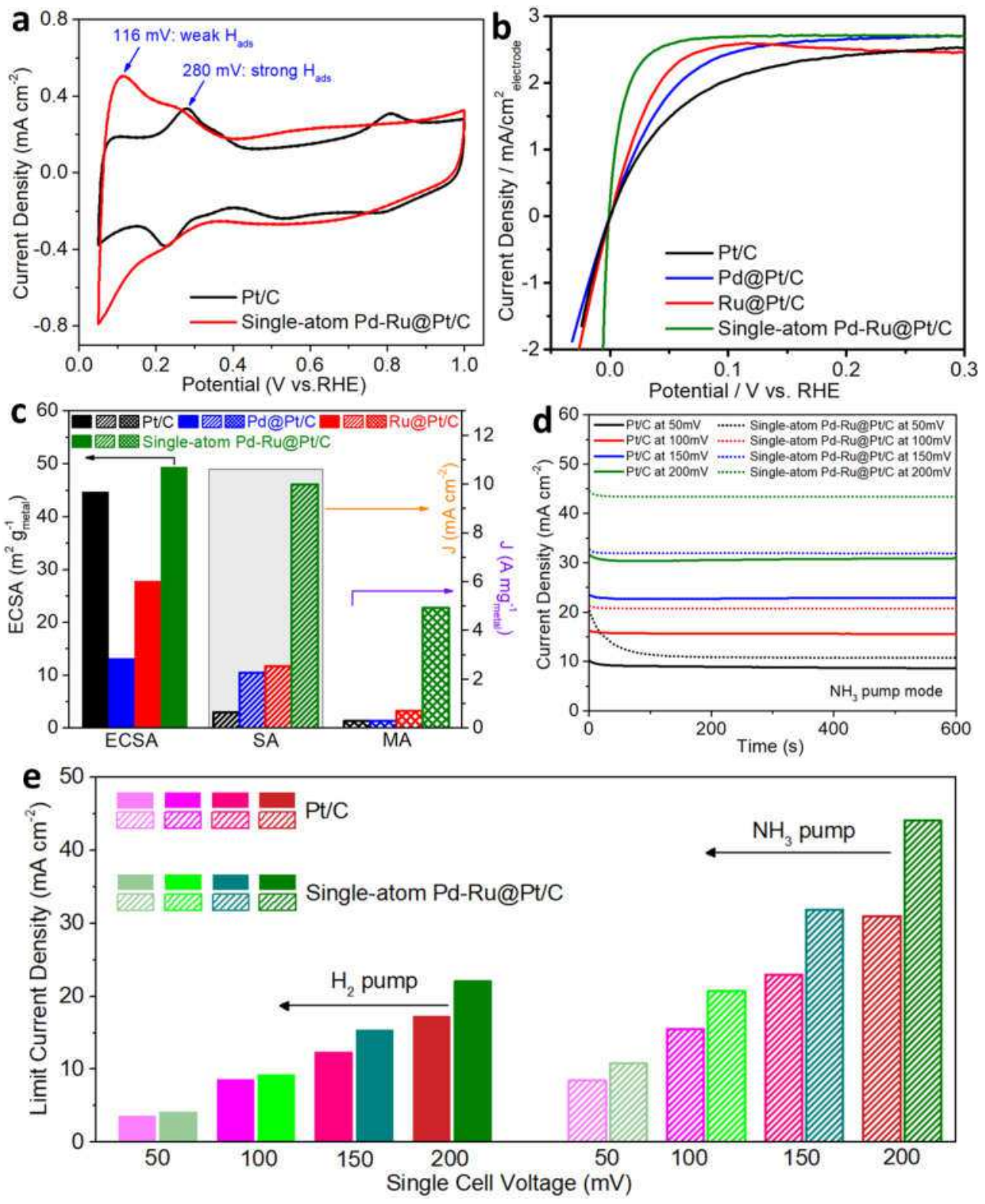

Fig. 6 Electrochemical performance and mechanism of different catalysts. (a) CV curves of different catalysts. Test condition: 0.05 to $1.00 \mathrm{~V}$ vs. RHE, $50 \mathrm{mV} / \mathrm{s}, \mathrm{N}_{2}$-saturated $0.1 \mathrm{M} \mathrm{KOH}$. (b) HOR polarization curves of different catalysts. Test condition: -0.05 to $0.40 \mathrm{~V} v s$. RHE, $10 \mathrm{mV} \mathrm{s}^{-}$ 1, $\mathrm{H}_{2}$-saturated 0.1M KOH, RDE at $1600 \mathrm{rpm}$. (c) Comparison of ECSA (black arrow, left axis), SA (normalized by ECSA, orange arrow, right axis) and MA (normalized by Pt mass, purple arrow, 
right axis) for HER at $50 \mathrm{mV}$ vs. RHE for all tested catalysts. (d) Gibbs Free energy profiles for catalysts at equilibrium potential and $\mathrm{pH}=14$. (e) Comparison of limit current density of $\mathrm{Pt} / \mathrm{C}$ and single-atom Pd-Ru@Pt/C under $\mathrm{H}_{2}$ pump and $\mathrm{NH}_{3}$ pump mode in electrochemical cell. Test condition: Nafion 211 membrane, $5 \mathrm{~cm}^{2}$ electrode, $25^{\circ} \mathrm{C}, 34 \%$ relative humidity (RH) for $\mathrm{H}_{2}-\mathrm{NH}_{3}$ mixture, 0.2 bar $\mathrm{H}_{2}-\mathrm{NH}_{3}$ mixture at flow rates of $50 \mathrm{~mL} \mathrm{~min}^{-1}$ of $\mathrm{H}_{2}$ and $100 \mathrm{~mL} \mathrm{~min}^{-1}$ of $\mathrm{NH}_{3}$.

The HOR performances of $\mathrm{Pd}-\mathrm{Ru} @ \mathrm{Pt} / \mathrm{C}$ and other reference catalysts $(\mathrm{Pt} / \mathrm{C}, \mathrm{Pd} @ \mathrm{Pt} / \mathrm{C}$, and $\mathrm{Ru} @ \mathrm{Pt} / \mathrm{C}$ ) were evaluated using linear sweep voltammetry (LSV) in an $\mathrm{N}_{2}$-saturated $0.1 \mathrm{M} \mathrm{KOH}$ electrolyte at a scan rate of $5 \mathrm{mV} \mathrm{s}^{-1}$ (Fig. 6b). The ECSAs of catalysts in alkaline electrolytes were further determined by measuring the under-potential hydrogen deposition $\left(\mathrm{H}_{\text {upd }}\right)^{7}$ for $\mathrm{Pt} / \mathrm{C}$ (Supplementary Fig. 9a) or the under-potential copper deposition $\left(\mathrm{Cu}_{\mathrm{upd}}\right)^{17}$ for $\mathrm{Pd}$ or $\mathrm{Ru}$ doped Pt catalysts (Supplementary Fig. 12) since hydrogen can absorb into the Pd leading to overestimated ECSA but only $\mathrm{Cu}$ monolayer absorbs on Pd surface. The single-atom Pd-Ru@Pt/C gave the highest ECSA of $49.3 \mathrm{~m}^{2} \mathrm{~g}_{\text {metal }}{ }^{-1}$ among all other catalysts including the $\mathrm{Pt} / \mathrm{C}\left(44.6 \mathrm{~m}^{2}\right.$ $\left.\mathrm{g}_{\text {metal }}{ }^{-1}\right), \mathrm{Pd} @ \mathrm{Pt} / \mathrm{C}\left(7.7 \mathrm{~m}^{2} \mathrm{~g}_{\text {metal }}{ }^{-1}\right)$, and Ru@Pt/C $\left(27.7 \mathrm{~m}^{2} \mathrm{~g}_{\text {metal }}{ }^{-1}\right)$ (Fig. 6c). Therefore, decorating single-atom $\mathrm{Pd}-\mathrm{Ru}$ on $\mathrm{Pt} / \mathrm{C}$ increases the ECSA. To quantitatively compare the intrinsic HOR activity, the kinetic currents were obtained from the current-potential response of each catalyst (Supplementary Fig. 11a-d) using the Koutecký-Levich equation. As shown in the KoutechýLevich plots (Supplementary Fig. 11e), the $\mathrm{j}^{-1}$ intercept $\left(1 / \mathrm{j}_{\mathrm{k}}\right)$ of the $\mathrm{Pd}-\mathrm{Ru} @ \mathrm{Pt} / \mathrm{C}$ catalyst (green) is much smaller than those of other reference catalysts. The calculated $\mathrm{j}_{\mathrm{k}}$ of the $\mathrm{Pd}-\mathrm{Ru} @ \mathrm{Pt} / \mathrm{C}$ catalyst is $20.2 \mathrm{~mA} \mathrm{~cm}{ }^{-2}$, which is 4.6 times higher than for the $\mathrm{Pt} / \mathrm{C}\left(4.3 \mathrm{~mA} \mathrm{~cm}{ }^{-2}\right)$. Therefore, the HOR kinetics on the Pd-Ru@Pt surface is the quickest. The SA and MA of the single-atom $\mathrm{Pd}-\mathrm{Ru} @ \mathrm{Pt} / \mathrm{C}$ at $50 \mathrm{mV}$ vs. RHE are $9.98 \mathrm{~mA} \mathrm{~cm}^{-2}$ and $4.93 \mathrm{~A} \mathrm{mg}^{-1}$ metal, respectively. These activities are 15.9 and 17.5 times higher than those for the $\mathrm{Pt} / \mathrm{C}$, respectively (Fig. 6c). To our knowledge, such a high HOR activity reported here for the $\mathrm{Pd}-\mathrm{Ru} @ \mathrm{Pt} / \mathrm{C}$ in an alkaline solution has not been achieved by any other nanomaterial under comparable conditions. Furthermore, the exchange current densities are obtained using the Koutecky-Levich equation and the ButlerVolmer equation (Method part). From Supplementary Fig. 13 and Supplementary Table 4, the specific exchange current density of $\mathrm{Pt} / \mathrm{C}$ was determined to be $0.29 \mathrm{~mA} \mathrm{~cm}^{-2} \mathrm{Pt}$, in agreement with previous report ${ }^{18}$. The specific exchange current density $\left(1.61 \mathrm{~mA} \mathrm{~cm}^{-2} \mathrm{Pt}\right)$ of single-atom $\mathrm{Pd}-\mathrm{Ru}$ pair was 5.5 times that of the $\mathrm{Pt} / \mathrm{C}\left(0.29 \mathrm{~mA} \mathrm{~cm}^{-2} \mathrm{Pt}\right), 2.6$ times of $\mathrm{Pd} @ \mathrm{Pt} / \mathrm{C}\left(0.62 \mathrm{~mA} \mathrm{~cm}{ }_{\mathrm{Pt}}^{-2}\right)$ and 1.8 times of $\mathrm{Ru} @ \mathrm{Pt} / \mathrm{C}\left(0.88 \mathrm{~mA} \mathrm{~cm}^{-2} \mathrm{Pt}\right)$. Normalized to metal mass, the mass exchange current density (0.79 mA mg ${ }^{-1}$ metal) of single-atom Pd-Ru@Pt/C was 6.0 times that of the $\mathrm{Pt} / \mathrm{C}(0.13 \mathrm{~mA}$ $\mathrm{mg}^{-1}$ metal $), 9.7$ times that of $\mathrm{Pd} @ \mathrm{Pt} / \mathrm{C}\left(0.08 \mathrm{~mA} \mathrm{mg}^{-1}\right.$ metal $)$ and 6.5 times that of $\mathrm{Ru} @ \mathrm{Pt} / \mathrm{C}(0.12 \mathrm{~mA}$ $\mathrm{mg}^{-1}$ metal). Therefore, either of $\mathrm{Pd}$ or $\mathrm{Ru}$ single-atom modification can only enhance the specific exchange current density of Pt, but it cannot improve the mass exchange current density of Pt. To contrast, the single-atom Pd-Ru pair effectively improves both the specific and mass exchange current density of Pt.

Moreover, the electrochemical durability of the Pd-Ru@Pt/C in an alkaline electrolyte was also assessed by accelerated stability tests between 0.05 and $0.4 \mathrm{~V}$ (vs. RHE) at $100 \mathrm{mV} \mathrm{s}^{-1}$ in $\mathrm{N}_{2-}$ 
saturated $0.1 \mathrm{M} \mathrm{KOH}$. The $\mathrm{CV}$ curve was recorded every 2,000 cycles. The ECSA retains more than $95 \%$ of the initial value during the cycling process (Supplementary Fig. 14). Furthermore, the SA and MA of the Pd-Ru@Pt/C after 10,000 cycles were still much higher than those for the Pt/C (17.7 and 19.6 times, respectively) (Supplementary Fig. 15-16).

To reveal the HOR reaction mechanism, the Gibbs Free Energy profile at an equilibrium potential of $-0.8 \mathrm{~V}$ with $\mathrm{pH}=14$ was calculated using DFT. The Gibbs Free energy profile (Fig. 6d) shows a more negative $\Delta \mathrm{G}$ of $\mathrm{H}^{*}$ for pristine $\mathrm{Pt}$ (111) when compared to both the $\mathrm{Pd} @ \operatorname{Pt}(111)$ and Pd-Ru@Pt (111) slabs. The $\mathrm{H}^{*}$ oxidation is endothermic with the Pd-Ru@Pt (111) surface catalyst showing the smaller barrier for $\mathrm{H}^{*}$ oxidation. The pristine $\mathrm{Pt}(111)$ catalyst has the highest thermodynamic free energy change value at an equilibrium potential for $\mathrm{H}^{*}$ oxidation. Therefore, the barrier for $\mathrm{H}^{*}$ oxidation decreases in the order: Pt (111)> Pd@Pt (111)> Pd-Ru@Pt (111). Following this discovery, the increased water adsorption strength on the Pd-Ru@Pt surface in alkaline electrolytes was validated by Fourier-transform infrared spectroscopy (FTIR). The relative absorbance of the $\mathrm{OH}$ stretching bands can be used to estimate the overall water organization changes. Water adsorption changes $\mathrm{OH}$ stretching modes in the region 3000-3500 $\mathrm{cm}^{-1}$ which are highly sensitive to water's hydrogen bond (HB) network. The broad band consists of two main components peaking at $3250\left(v_{1}\right)$ and $3400 \mathrm{~cm}^{-1}\left(v_{2}\right)$, which relate to water molecules in tetrahedral-bonded ice-like organization and an HB-distorted liquid environment, respectively. ${ }^{19}$ The increase of the bands absorbance at $3250 \mathrm{~cm}^{-1}$ demonstrates a higher coordination of water molecules. As shown in Supplementary Fig. 17, the ratio R of $v_{1}: v_{2}$ increases in the order: $\mathrm{R}(0.1 \mathrm{M} \mathrm{KOH})<\mathrm{R}(\mathrm{Pt} / \mathrm{C} 0.1 \mathrm{M} \mathrm{KOH})<\mathrm{R}(\mathrm{Pd}-\mathrm{Ru} @ \mathrm{Pt} / \mathrm{C} 0.1 \mathrm{M} \mathrm{KOH})$, indicating the increased coordination and water-substance interaction strength. Furthermore, the $\Delta \mathrm{G}$ of $\mathrm{H}_{2} \mathrm{O}$ desorption on different catalysts was calculated, assuming $0 \mathrm{eV}$ on a pristine $\mathrm{Pt}$ (111) surface as reference. Since the $\mathrm{H}_{2} \mathrm{O}$ desorption is endothermic for both $\mathrm{Pd}-\mathrm{Ru}$ and $\mathrm{Pd}$ doped catalysts, the $\mathrm{Pd}-\mathrm{Ru} @ \mathrm{Pt}$ (111) surface showed the larger $\mathrm{H}_{2} \mathrm{O}$ desorption barrier $(0.45 \mathrm{eV})$ when compared to the Pd@Pt (111) surface $(0.18 \mathrm{eV})$ (Fig. 6d). Therefore, both FTIR and simulation confirmed that $\mathrm{H}_{2} \mathrm{O}$ has a stronger interaction with Pd-Ru@Pt (111), which in turn weakens the hydrogen binding and increases the HOR activity.

Additionally, the single-atom Pd-Ru@Pt/C increases the HER activity (Supplementary Fig. 18-18). As shown in Supplementary Fig. 19a, the overpotential of the Pd-Ru@Pt/C at $10 \mathrm{~mA} \mathrm{~cm}^{-}$ 2 is $32 \mathrm{mV}$ less than that of the benchmark Pt/C. At $50 \mathrm{mV}$ vs. RHE, the SA $\left(1.59 \mathrm{~mA} \mathrm{~cm}^{-2}\right)$ and MA (0.78 $\mathrm{A} \mathrm{mg}^{-1}{ }_{\text {metal }}$ ) of the Pd-Ru@Pt/C are double the Pt/C values (Supplementary Fig. 19b).

In a proof-of-principle demonstration of practical application, we compared the bifunctional hydrogen electrocatalytic activity of Pt/C and Pd-Ru@Pt/C using a $5 \mathrm{~cm}^{2} \mathrm{H}_{2}$ pump cell and $\mathrm{NH}_{3}$ pump cell (Supplementary Fig. 20). The Pd-Ru@Pt/C delivered 1.2 times steady current density than the $\mathrm{Pt} / \mathrm{C}$ in the $\mathrm{H}_{2}$ pump mode (Supplementary Fig. 21), indicating enhanced HOR and HER performance in acidic environments. The Pd-Ru@Pt/C also showed a 1.4 times higher steady current value than the $\mathrm{Pt} / \mathrm{C}$ in the $\mathrm{NH}_{3}$ pump mode in alkaline environments (Supplementary Fig. 22 and Fig. 6e), which is consistent with the advantage of optimized surface micro-environments 
via single-atom $\mathrm{Pd}-\mathrm{Ru}$ doping in the presence of $\mathrm{OH}^{-}$. The remarkable $\mathrm{HOR}$ and $\mathrm{HER}$ performance of the $\mathrm{Pd}-\mathrm{Ru} @ \mathrm{Pt} / \mathrm{C}$ is further demonstrated in the high pressure $\mathrm{NH}_{3}$ compression mode, as shown in Supplementary Fig. 23.

\section{Conclusion}

Single-atom $\mathrm{Pd}-\mathrm{Ru}$ decoration on $\mathrm{Pt}$ nanoparticles (single-atom $\mathrm{Pd}-\mathrm{Ru} @ \mathrm{Pt}$ ) was synthesized by trapping the high-temperature-evaporated $\mathrm{Pd}$ and $\mathrm{Ru}$ atoms from precursors onto the Pt nanoparticle surface. The stable single-atom Pd-Ru@Pt structure is verified by both EXAFS and DFT simulations. The SA and MA of the single-atom Pd-Ru@Pt/C for the HOR are $9.98 \mathrm{~mA}$

$\mathrm{cm}^{-2}$ and $4.93 \mathrm{~A} \mathrm{mg}^{-1}$ metal, which are 15.9 and 17.5 times higher than that of the state-of-the-art $\mathrm{Pt} / \mathrm{C}$, respectively. For the HER, the SA $\left(1.59 \mathrm{~mA} \mathrm{~cm}^{-2}\right)$ and MA $\left(0.78 \mathrm{~A} \mathrm{mg}^{-1}\right.$ metal $)$ of the singleatom Pd-Ru@Pt/C are also twice as high as that of the Pt/C. DFT shows that the dopants modify the electronic structure of the Pt (111) surface by changing the states near the Fermi level and shifting the $(d)$ band center of the outermost Pt atoms further away from the Fermi level, effectively weakening hydrogen chemisorption strength. Moreover, DFT and AIMD simulations show the continued dopant stability and preferred adsorption mode in the presence of a liquid environment as well as the efficiency of the hydrogen spillover in the presence of co-dopants. Practically, the enhanced HOR and HER performances of the single-atom Pd-Ru@Pt/C is validated by $\mathrm{NH}_{3}$ and $\mathrm{H}_{2}$ electrochemical pump performance. The demonstrated electrochemical device can easily be scaled up on demand. With renewable energy as the power input, our method represents an efficient, distributed, and sustainable $\mathrm{NH}_{3}$ and $\mathrm{H}_{2}$ separation and/or compression with broad scientific and technical impacts.

\section{Methods}

Synthesis of electrocatalysts. All chemicals were purchased from Sigma-Aldrich unless otherwise specified. Pt nanoparticles supported on carbon black were prepared via a solvothermal technique following previously reported procedures ${ }^{20}$. Typically, $2.5 \mathrm{~mL}$ of $\mathrm{H}_{2} \mathrm{PtCl}_{6}$ solution (40 $\mathrm{mM}$ in ethylene glycol (EG)) was added into $60 \mathrm{~mL}$ EG. The $\mathrm{pH}$ of the solution was adjusted to 12 by adding $1 \mathrm{M} \mathrm{NaOH}$ in EG. Then, $80 \mathrm{mg}$ of carbon black was added to the above solution and stirred for $1 \mathrm{~h}$. The solution was heated at $120^{\circ} \mathrm{C}$ for $4 \mathrm{~h}$. After cooling down, the $\mathrm{pH}$ of the reaction solution was adjusted to $<3$ using $2 \mathrm{M} \mathrm{HNO}_{3}$ aqueous solution, then $40 \mathrm{~mL}$ water was added and stirred for $10 \mathrm{~h}$. The resulting catalyst was washed with DI water until $\mathrm{Cl}^{-}$was not detected by silver nitrate titration method and then vacuum dried overnight at $80^{\circ} \mathrm{C}$, denoted as $\mathrm{Pt} / \mathrm{C}$.

Atomic $\mathrm{Pd}-\mathrm{Ru}$ doped $\mathrm{Pt} / \mathrm{C}$ was synthesized by the catalytic pyrolysis method. In detail, $2.5 \mathrm{mg}$ of $\mathrm{Ru}(\mathrm{acac})_{3}$ and $2.5 \mathrm{mg}$ of $\mathrm{Pd}(\mathrm{acac})_{2}$ were mixed and transferred into a combustion boat, which was transferred to a glass tube. A silicon wafer with $20 \mathrm{mg}$ of $\mathrm{Pt} / \mathrm{C}$ was put into the tube. Then the tube was sealed under vacuum and underwent thermal treatment before being cooled to room temperature in the tube furnace. Thermal treatment detail: Increase temperature from $30^{\circ} \mathrm{C}$ to $300^{\circ} \mathrm{C}$ 
over $2 \mathrm{~h}$ and hold at $300^{\circ} \mathrm{C}$ for $60 \mathrm{~min}$. $\mathrm{Pd}$ or Ru doped $\mathrm{Pt} / \mathrm{C}$ was obtained using similar procedure, except that $5 \mathrm{mg} \mathrm{Ru}(\mathrm{acac})_{2}$ or $\mathrm{Pd}(\mathrm{acac})_{2}$ was used instead of bi-salt mixture.

Material characterizations. The catalyst morphology was characterized by a JEOL $2100 \mathrm{~F}$ field emission TEM with an electron accelerating voltage of $200 \mathrm{keV}$. EDS was obtained on a Hitachi SU-70 FEG SEM coupled with a Bruker EDS system. The X-ray diffraction (XRD) was conducted with a Bruker D8 X-ray diffractometer ( $\mathrm{Cu} \mathrm{K \alpha}$ radiation, $\lambda=1.5418 \AA$ ). X-ray photoelectron spectroscopy (XPS) was performed on a high sensitivity Kratos Axis $165 \mathrm{X}$-ray photoelectron spectrometer equipped with $\mathrm{Mg} \mathrm{K \alpha}$ radiation. The binding-energy was calibrated using the $\mathrm{C} 1 \mathrm{~s}$ peak of carbon at $284.8 \mathrm{eV}$. Fourier transform infrared spectroscopy (FTIR) was recorded by a NEXUS 670 FT-IR Instrument. XAS measurements were performed at the 7-BM beamline of the National Synchrotron Light Source II (NSLS II) at Brookhaven National Laboratory in the transmission mode. The X-ray absorption near edge structure and Extended X-ray absorption fine structure spectra were processed using the Athena software package. The AUTOBK code was used to normalize the absorption coefficient, and separate the EXAFS signal, $\chi(\mathrm{k})$, from the isolate atom-absorption background. The extracted EXAFS signal, $\chi(\mathrm{k})$, was weighted by $\mathrm{k}^{3}$ to emphasize the high-energy oscillations and then Fourier-transformed in a k range from 3.0 to $10.5 \AA^{-1}$ to analyze the data in R space.

Electrochemical measurements for the HOR and HER. To prepare the catalyst ink, $5 \mathrm{mg}$ catalyst and $20 \mu \mathrm{L} 5 \mathrm{wt} \%$ Nafion 117 solution were dispersed in $2.5 \mathrm{~mL}$ ethanol. Then, $4 \mu \mathrm{L}$ ink was drop-cast on a glassy carbon electrode $\left(0.196 \mathrm{~cm}^{2}\right)$ for the RDE test. A mercury/mercury oxide electrode was utilized as the reference electrode, with a graphite rod as the counter electrode. Cyclic voltammetry (CV) was performed in a $\mathrm{N}_{2}$-saturated $0.1 \mathrm{M} \mathrm{KOH}$ electrolyte with a potential scan rate of $50 \mathrm{mVs}^{-1}$. The electrochemical active surface area (ECSA) of $\mathrm{Pt} / \mathrm{C}$ was determined by integrating the hydrogen adsorption charge on the CV curve by assuming $210 \mu \mathrm{C} / \mathrm{cm}^{2}$ for the adsorption of a hydrogen monolayer. All of the other catalyst ECSAs were obtained by means of copper underpotential deposition $\left(\mathrm{Cu}_{\text {upd }}\right)$. For the $\mathrm{Cu}$ underpotential deposition/stripping experiments, an $\mathrm{N}_{2}$-saturated solution containing $2 \mathrm{mM} \mathrm{CuSO}_{4}$ and $0.05 \mathrm{M} \mathrm{H}_{2} \mathrm{SO}_{4}$ was used as the electrolyte. For single-atom Pd-Ru@Pt/C and Ru@Pt/C, the electrode potential was first held at $0.95 \mathrm{~V}$ to oxidize all $\mathrm{Ru}$ sites. For other catalysts, there was no need to hold the electrode potential at $0.95 \mathrm{~V}$ before $\mathrm{Cu}_{\text {upd. }}$. The potential was held at $0.3 \mathrm{~V}$ versus RHE for $300 \mathrm{~s}$ to form a $\mathrm{Cu}_{\text {upd }}$ monolayer, and then followed by a linear scan to $0.95 \mathrm{~V}$ at $5 \mathrm{mV} \mathrm{s}^{-1}$. The ECSAs were calculated by subtracting the background CVs that were collected in the $\mathrm{N}_{2}$-saturated $0.05 \mathrm{M} \mathrm{H}_{2} \mathrm{SO}_{4}$ at $5 \mathrm{mV}$ $\mathrm{s}^{-1}$, assuming a charge density of $470 \mu \mathrm{C} \mathrm{cm}^{-2}$. The HOR and HER tests were conducted with a working glassy carbon electrode rotation speed of $1,600 \mathrm{rpm}$ in an $\mathrm{H}_{2}$-saturated $0.1 \mathrm{M} \mathrm{KOH}$ electrolyte with a potential scan rate of $10 \mathrm{mVs}^{-1}$. Accelerated durability tests were conducted by cycling between $0.05 \mathrm{~V}$ and $0.4 \mathrm{~V}$ versus RHE at $100 \mathrm{mV} \mathrm{s}^{-1}$ in $\mathrm{N}_{2}$-saturated $0.1 \mathrm{M} \mathrm{KOH}$.

The kinetic current density $\left(j_{k}\right)$ was obtained using the Koutecky-Levich equation (Eq. 2):

$\frac{1}{j}=\frac{1}{j_{d}}+\frac{1}{j_{k}}$

Eq. 2 
where $j$ was the measured current density ( $\mathrm{mA} \mathrm{cm}^{-2}$ electrode), $j_{k}$ was the kinetic current density ( $\mathrm{mA} \mathrm{cm}{ }^{-2}$ electrode), and $j_{d}$ was the diffusion limit current density $\left(\mathrm{mA} \mathrm{cm}^{-2}\right.$ electrode).

The exchange current densities $\left(j_{0}\right)$ was obtained by fitting $j_{k}$ to the Butler-Volmer equation (Eq. 3):

$$
j_{k}=j_{0} A_{r f}\left[e^{\frac{\alpha F}{R T} \eta}-e^{\frac{-(1-\alpha) F}{R T} \eta}\right]
$$

where $j_{0}$ was the exchange current densities $\left(\mathrm{mA} \mathrm{cm}{ }^{-2} \mathrm{Pt}\right), A_{v f}$ is the roughness factor, defined as the ratio between the electrochemical surface area and the geometric area of the disk $\left(\mathrm{cm}^{2}{ }_{\mathrm{Pt}} \mathrm{cm}^{-}\right.$ $\left.2_{\text {electrode }}\right), \alpha$ is the transfer coefficient, $\mathrm{F}$ was the Faraday constant $\left(96485 \mathrm{C} \mathrm{mol}^{-1}\right), \mathrm{R}$ was the universal gas constant $\left(8.314 \mathrm{~J} \mathrm{~mol}^{-1} \mathrm{~K}^{-1}\right)$, T was the absolute temperature $(\mathrm{K})$, and $\eta$ is the overpotential (V).

Electrochemical measurements for $\mathrm{H}_{2}$ pump and $\mathrm{NH}_{3}$ pump. Both the cathode and anode catalyst loading were $0.2 \mathrm{mg}_{\text {metal }} \mathrm{cm}^{-2}$ for Pt/C and single-atom Pd-Ru@Pt/C. For the $\mathrm{H}_{2}$ pump, a Nafion 211 membrane was used with $5 \mathrm{~cm}^{2}$ active area operated at $25^{\circ} \mathrm{C}, 76 \%$ relative humidity $(\mathrm{RH})$, and 0.2 bar of $\mathrm{H}_{2}$ at a flow rate of $50 \mathrm{~mL} \mathrm{~min}^{-1}$ of $\mathrm{H}_{2}$. For the $\mathrm{NH}_{3}$ pump, a Nafion 211 membrane was used with $5 \mathrm{~cm}^{2}$ active area operated at $25{ }^{\circ} \mathrm{C}, 34 \%$ relative humidity (RH), and 0.2 bar for an $\mathrm{H}_{2}-\mathrm{NH}_{3}$ mixture at flow rates of $50 \mathrm{~mL} \mathrm{~min}^{-1}$ of $\mathrm{H}_{2}$ and $200 \mathrm{~mL} \mathrm{~min}^{-1}$ of $\mathrm{NH}_{3}$.

Computational Details. Density functional theory (DFT) calculations were performed using the Vienna ab-initio simulation package (VASP) $\operatorname{code}^{21,22}$ with the projector augmented wave (PAW) pseudopotentials $^{23}$. Generalized gradient approximation (GGA) of Perdew-Burke-Ernzerhof (PBE) functionals were used to implement electron exchange-correlation interactions with a kinetic energy cutoff of $400 \mathrm{eV}^{24}$. The self-consistent field (SCF) and geometry convergence tolerance were set to $1 \times 10^{-4}$ and $1 \times 10^{-3} \mathrm{eV}$, respectively. For geometry optimization calculations, a $\Gamma$-point-centered Monkhorst-Pack reciprocal grid of $5 \times 5 \times 1 \mathrm{k}$-points was used for first Brillouin zone sampling. Meanwhile, a $\Gamma$-point was used for ab-initio molecular dynamics (AIMD) simulations at room temperature. The room temperature was maintained using Nosé-Hoover chains $\mathrm{s}^{25}$, with configurations belonging to the canonical $(\mathrm{N}, \mathrm{V}, \mathrm{T})$ ensemble with a time step set to $1 \mathrm{fs}$. To mimic the water environment, the Amorphous Cell module from Materials Studio was used to pack the water molecules on top of the Pt (111) surface at a $1 \mathrm{~g} / \mathrm{cc}$ density. To represent an alkaline environment, $\mathrm{K}^{+}$and $\mathrm{OH}^{-}$species where introduced in the bulk of the water region. To explicitly include electric fields $(0.2 \mathrm{~V} / \AA)$ in the calculations, a vacuum space greater than $10 \AA$ was introduced in the normal direction on top of the water molecules. The method by Neugebauer et al. ${ }^{26}$ and improved by Feibelman ${ }^{27}$ was used to explicitly include electric fields. The van der Wals (vdW) interaction was described with DFT-D3 method. ${ }^{28}$ We used quantum-based electronic descriptors such as partial density of states (PDOS), obtained using the LOBSTER (Local Orbital Basis Suite Towards Electronic-Structure Reconstruction) program ${ }^{29}$, to measure the interacting nature of atomic orbital pairs.

In order to model the Pt surfaces, a Pt slab cleaved along the (111) facet for five-layer slabs and three-layer slabs were used for geometry optimization calculations and AIMD simulations, 
respectively. For the five-layer slab calculations, the top three layers in each slab were sufficiently relaxed in the calculations, whereas the bottom two layers were fixed at their bulk configurations. In order to avoid the computational cost of a five-layer slab, AIMD simulations were carried out on a reduced three-layer surface slab model. Calculations of hydrogen binding energies $\left(\Delta \mathrm{E}_{\mathrm{HBE}}\right)$ were performed according to the following equation:

$\Delta E_{H B E}=\mathrm{E}_{\text {Tот }}(\mathrm{Pt}$ slab + adsorbed species $)-\mathrm{E}_{\text {Slab }}(\mathrm{Pt}$ slab $)-\mathrm{E}_{\text {Species }} \frac{1}{2}\left(\mathrm{H}_{2}\right) \quad$ Eq. 2

Here, $\mathrm{E}_{\text {TOт }}\left(\mathrm{Pt}\right.$ slab + adsorbed species) is the total energy of the system. Then, $\mathrm{E}_{\text {Slab }}(\mathrm{Pt}$ slab) and $\mathrm{E}_{\text {Species }}\left(\mathrm{H}_{2}\right)$ are the energies of the $\mathrm{Pt}(111)$ slab and the $\mathrm{H}_{2}$ molecule, respectively. Calculation of the $\mathrm{H}_{2}$ molecule was obtained by placing the atom in a $1 \mathrm{~nm}$ cube. To obtain the Gibbs Free Energy profiles of the HOR at $0 \mathrm{~V}$ and equilibrium potential, we followed the thermodynamic pathways of the HOR as described in the work of Wei and co-workers ${ }^{30}$. The Open Visualization Tool (OVITO) ${ }^{31}$ was used to visualize all the configurations and models.

\section{Reference}

1. Durst, J.; Siebel, A.; Simon, C.; Hasché, F.; Herranz, J.; Gasteiger, H. A. New insights into the electrochemical hydrogen oxidation and evolution reaction mechanism. Energy \& Environmental Science 2014, 7, (7), 2255-2260.

2. Sheng, W.; Zhuang, Z.; Gao, M.; Zheng, J.; Chen, J. G.; Yan, Y. Correlating hydrogen oxidation and evolution activity on platinum at different $\mathrm{pH}$ with measured hydrogen binding energy. Nature Communications 2015, 6, 5848.

3. Strmcnik, D.; Uchimura, M.; Wang, C.; Subbaraman, R.; Danilovic, N.; van der Vliet, D.; Paulikas, A. P.; Stamenkovic, V. R.; Markovic, N. M. Improving the hydrogen oxidation reaction rate by promotion of hydroxyl adsorption. Nature Chemistry 2013, 5, 300.

4. Tao, Y.; Gibbons, W.; Hwang, Y.; Radermacher, R.; Wang, C. Electrochemical ammonia compression. Chemical Communications 2017, 53, (41), 5637-5640.

5. $\quad$ Scofield, M. E.; Zhou, Y.; Yue, S.; Wang, L.; Su, D.; Tong, X.; Vukmirovic, M. B.; Adzic, R. R.; Wong, S. S. Role of Chemical Composition in the Enhanced Catalytic Activity of Pt-Based Alloyed Ultrathin Nanowires for the Hydrogen Oxidation Reaction under Alkaline Conditions. ACS Catalysis 2016, $6,(6), 3895-3908$.

6. Schwammlein, J. N.; El-Sayed, H. A.; Stuhmeier, B. M.; Wagenbauer, K. F.; Dietz, H.; Gasteiger, H. A. Origin of Superior Activity of Ru@Pt Core-Shell Nanoparticles towards Hydrogen Oxidation in Alkaline Media. ECS Transactions 2016, 75, (14), 971-982.

7. Li, M.; Duanmu, K.; Wan, C.; Cheng, T.; Zhang, L.; Dai, S.; Chen, W.; Zhao, Z.; Li, P.; Fei, H.; Zhu, Y.; Yu, R.; Luo, J.; Zang, K.; Lin, Z.; Ding, M.; Huang, J.; Sun, H.; Guo, J.; Pan, X.; Goddard, W. A.; Sautet, P.; Huang, Y.; Duan, X. Single-atom tailoring of platinum nanocatalysts for high-performance multifunctional electrocatalysis. Nature Catalysis 2019, 2, (6), 495-503.

8. Subbaraman, R.; Tripkovic, D.; Strmcnik, D.; Chang, K.-C.; Uchimura, M.; Paulikas, A. P.; Stamenkovic, V.; Markovic, N. M. Enhancing Hydrogen Evolution Activity in Water Splitting by Tailoring $\mathrm{Li}^{+}-\mathrm{Ni}(\mathrm{OH})_{2}$-Pt Interfaces. Science 2011, 334, (6060), 1256.

9. Zhang, J.; Sasaki, K.; Sutter, E.; Adzic, R. R. Stabilization of Platinum Oxygen-Reduction Electrocatalysts Using Gold Clusters. Science 2007, 315, (5809), 220-222.

10. Cao, L.; Zhang, G.; Jiang, S.; Tang, X.; Qin, X.; Guo, X.; Shao, Z.; Yi, B. Enhancing the Oxygen Reduction Reaction Performance by Modifying the Surface of Platinum Nanoparticles. ChemElectroChem 2016, 3, (2), 309-317. 
11. Qu, Y.; Li, Z.; Chen, W.; Lin, Y.; Yuan, T.; Yang, Z.; Zhao, C.; Wang, J.; Zhao, C.; Wang, X.; Zhou, F.; Zhuang, Z.; Wu, Y.; Li, Y. Direct transformation of bulk copper into copper single sites via emitting and trapping of atoms. Nature Catalysis 2018, 1, (10), 781-786.

12. Zhu, Y.; Cao, T.; Cao, C.; Luo, J.; Chen, W.; Zheng, L.; Dong, J.; Zhang, J.; Han, Y.; Li, Z.; Chen, C.; Peng, Q.; Wang, D.; Li, Y. One-Pot Pyrolysis to N-Doped Graphene with High-Density Pt Single Atomic Sites as Heterogeneous Catalyst for Alkene Hydrosilylation. ACS Catalysis 2018, 8, (11), 1000410011.

13. He, P.; Xu, B.; Xu, X.; Song, L.; Wang, X. Surfactant encapsulated palladium-polyoxometalates: controlled assembly and their application as single-atom catalysts. Chemical Science 2016, 7, (2), 10111015.

14. Wang, Z.; Xu, S.-M.; Xu, Y.; Tan, L.; Wang, X.; Zhao, Y.; Duan, H.; Song, Y.-F. Single Ru atoms with precise coordination on a monolayer layered double hydroxide for efficient electrooxidation catalysis. Chemical Science 2019, 10, (2), 378-384.

15. Mercer, M. P.; Hoster, H. E. Electrochemical Kinetics: a Surface Science-Supported Picture of Hydrogen Electrochemistry on $\mathrm{Ru}(0001)$ and $\mathrm{Pt} / \mathrm{Ru}(0001)$. Electrocatalysis 2017, 8, (6), 518-529.

16. Sheng, W.; Zhuang, Z.; Gao, M.; Zheng, J.; Chen, J. G.; Yan, Y. Correlating hydrogen oxidation and evolution activity on platinum at different $\mathrm{pH}$ with measured hydrogen binding energy. Nature Communications 2015, 6, (1), 5848.

17. Wang, Y.; Wang, G.; Li, G.; Huang, B.; Pan, J.; Liu, Q.; Han, J.; Xiao, L.; Lu, J.; Zhuang, L. Pt$\mathrm{Ru}$ catalyzed hydrogen oxidation in alkaline media: oxophilic effect or electronic effect? Energy \& Environmental Science 2015, 8, (1), 177-181.

18. Schmidt, T. J.; Ross, P. N.; Markovic, N. M. Temperature dependent surface electrochemistry on Pt single crystals in alkaline electrolytes: Part 2. The hydrogen evolution/oxidation reaction. Journal of Electroanalytical Chemistry 2002, 524-525, 252-260.

19. Petit, T.; Puskar, L.; Dolenko, T.; Choudhury, S.; Ritter, E.; Burikov, S.; Laptinskiy, K.; Brzustowski, Q.; Schade, U.; Yuzawa, H.; Nagasaka, M.; Kosugi, N.; Kurzyp, M.; Venerosy, A.; Girard, H.; Arnault, J.-C.; Osawa, E.; Nunn, N.; Shenderova, O.; Aziz, E. F. Unusual Water Hydrogen Bond Network around Hydrogenated Nanodiamonds. The Journal of Physical Chemistry C 2017, 121, (9), 51855194.

20. Zhang, S.; Shao, Y.; Yin, G.; Lin, Y. Carbon nanotubes decorated with Pt nanoparticles via electrostatic self-assembly: a highly active oxygen reduction electrocatalyst. Journal of Materials Chemistry 2010, 20, (14), 2826-2830.

21. Kresse, G.; Hafner, J. Ab initio molecular dynamics for liquid metals. Physical Review B 1993, 47, (1), 558-561.

22. Kresse, G.; Furthmüller, J. Efficiency of ab-initio total energy calculations for metals and semiconductors using a plane-wave basis set. Computational Materials Science 1996, 6, (1), 15-50.

23. Blöchl, P. E. Projector augmented-wave method. Physical Review B 1994, 50, (24), 17953-17979.

24. Perdew, J. P.; Burke, K.; Ernzerhof, M. Generalized Gradient Approximation Made Simple. Physical Review Letters 1996, 77, (18), 3865-3868.

25. Martyna, G. J.; Klein, M. L.; Tuckerman, M. Nosé-Hoover chains: The canonical ensemble via continuous dynamics. The Journal of Chemical Physics 1992, 97, (4), 2635-2643.

26. Neugebauer, J.; Scheffler, M. Adsorbate-substrate and adsorbate-adsorbate interactions of Na and K adlayers on Al(111). Physical Review B 1992, 46, (24), 16067-16080.

27. Feibelman, P. J. Surface-diffusion mechanism versus electric field: $\mathrm{Pt} / \mathrm{Pt}(001)$. Physical Review $B$ 2001, 64, (12), 125403.

28. Grimme, S.; Antony, J.; Ehrlich, S.; Krieg, H. A consistent and accurate ab initio parametrization of density functional dispersion correction (DFT-D) for the 94 elements H-Pu. The Journal of Chemical Physics 2010, 132, (15), 154104.

29. Maintz, S.; Deringer, V. L.; Tchougréeff, A. L.; Dronskowski, R. LOBSTER: A tool to extract chemical bonding from plane-wave based DFT. Journal of Computational Chemistry 2016, 37, (11), 10301035 . 
30. Feng, Z.; Li, L.; Zheng, X.; Li, J.; Yang, N.; Ding, W.; Wei, Z. Role of Hydroxyl Species in Hydrogen Oxidation Reaction: A DFT Study. The Journal of Physical Chemistry C 2019, 123, (39), 2393123939.

31. Stukowski, A. Visualization and analysis of atomistic simulation data with OVITO-the Open Visualization Tool. Modelling and Simulation in Materials Science and Engineering 2009, 18, (1), 015012.

\section{Acknowledgement}

L. Cao and C. Wang at the University of Maryland gratefully acknowledge funding support from the Advanced Research Projects Agency-Energy under Contract No. DEAR0000962. E. Hu and X.-Q. Yang at Brookhaven National Laboratory (BNL) were supported by the Assistant Secretary for Energy Efficiency and Renewable Energy, Vehicle Technology Office of the U.S. Department of Energy through the Advanced Battery Materials Research (BMR) Program under contract DESC0012704. This research used beamlines 7-BM of the National Synchrotron Light Source II, a U.S. DOE Office of Science User Facility operated for the DOE Office of Science by Brookhaven National Laboratory under Contract No. DE-SC0012704. Computational resources from Texas A\&M Supercomputing Center and from Texas Advanced Computing Center at UT Austin are gratefully acknowledged.

\section{Author contributions}

L. Cao, F. Soto, and D. Li conceived the idea. L. Cao and D. Li performed the electrochemical experiments. L. Cao synthesized the catalysts. L. Cao, D. Li, and T. Deng carried out characterizations. E. Hu, and X.-Q. Yang performed and analyzed EXAFS and XANES analysis. F. Soto and P. Balbuena proposed the mechanism research and simulations. All authors contributed to writing of the manuscript.

\section{Competing interests}

The authors declare no competing interests. 


\section{Figures}

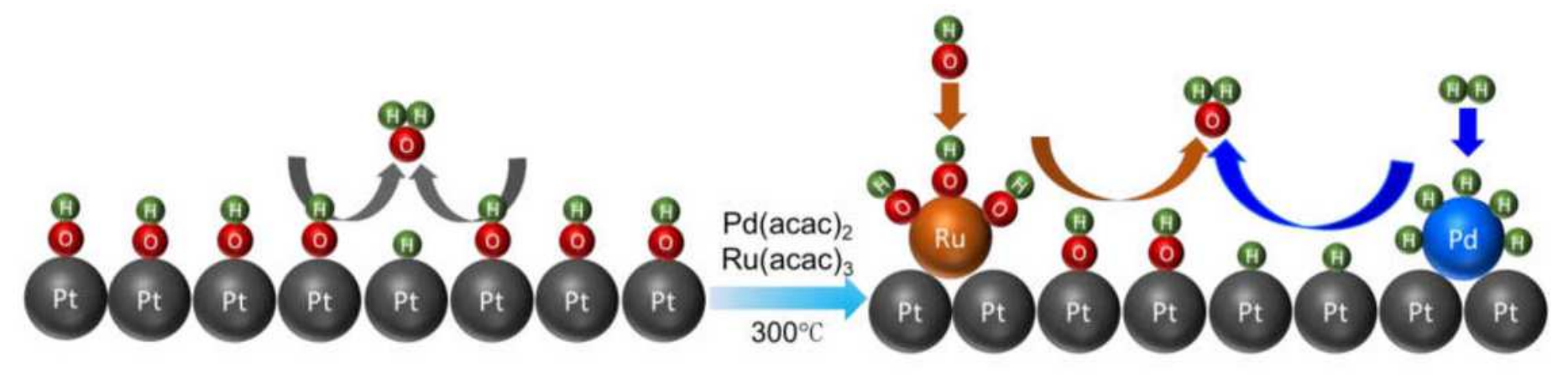

Figure 1

Hydrogen oxidation reaction schematic diagram on Pt and single-atom Pd-Ru@Pt surface. The decoration of Pt nanoparticles with paired single-atom Pd-Ru species increases the availability of Hads and OHads on the Pt surface to boost the specific catalytic activity for the HOR without sacrificing the ECSA. 

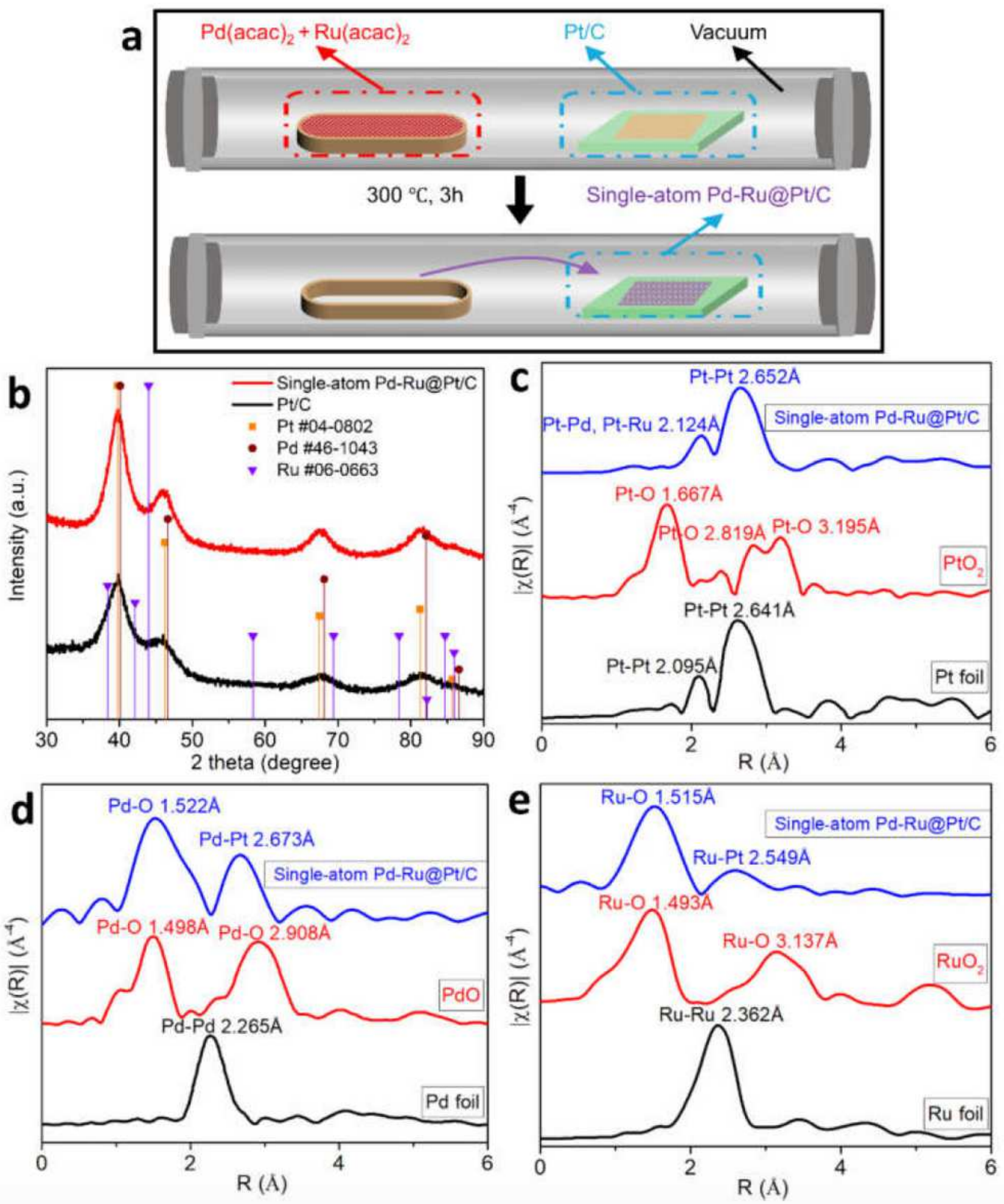

\section{Figure 2}

Preparation and structure characterization of electrocatalysts. (a) Scheme for synthesizing single-atom Pd-Ru@Pt through a chemical vapor deposition (CVD) setup. (b) X-ray diffraction (XRD) pattern of singleatom Pd-Ru@Pt/C and Pt/C. (c) Pt, (d) Pd and (e) Ru Extended X-Ray Absorption Fine Structure (EXAFS) fitting results of single-atom $\mathrm{Pd}-\mathrm{Ru} @ \mathrm{Pt} / \mathrm{C}$. 


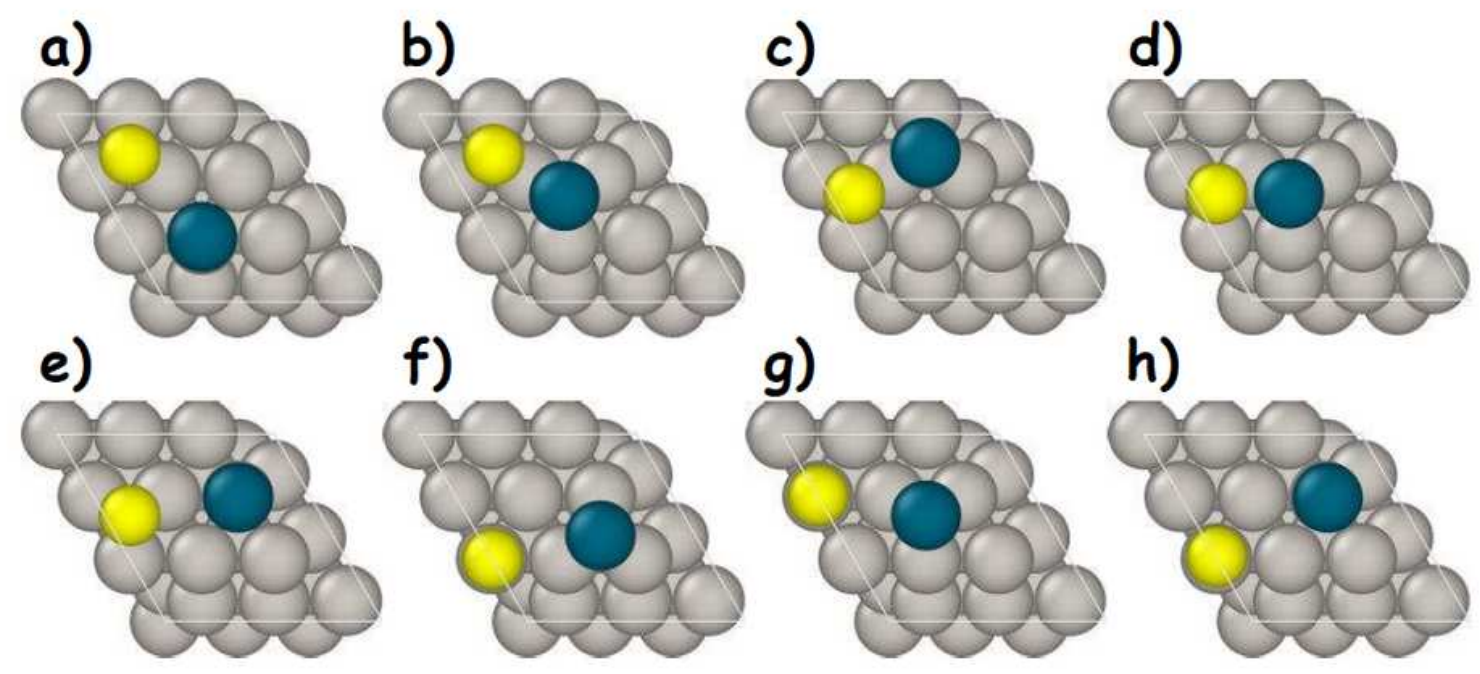

\section{Figure 3}

Top view of the configurations simulated for Pd (dark green) and Ru (yellow) deposition on top of a Pt (111) surface (gray). Ru adsorbed at the hcp site and Pd adsorbed at the top site (a), Ru adsorbed at the hcp site and Pd adsorbed at the fcc site (b), Ru adsorbed at the fcc site and Pd adsorbed at the hcp site (c), Ru adsorbed at the fcc site and Pd adsorbed at the fcc site (d), Ru adsorbed at the fcc site and Pd adsorbed at the top site (e), Ru adsorbed at the top site and Pd adsorbed at the hcp site (f), Ru adsorbed at the top site and Pd adsorbed at the fcc site (g) and Ru adsorbed at the top site and Pd adsorbed at the top site (h).

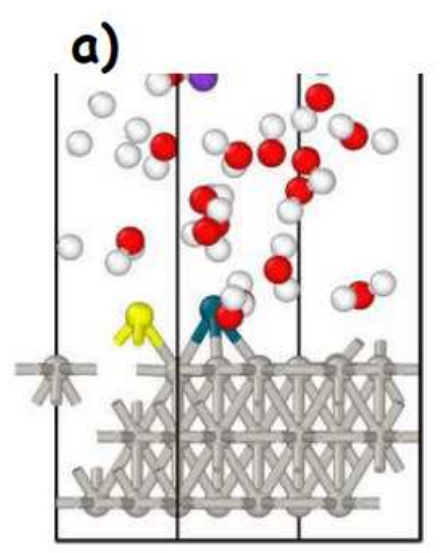

b)

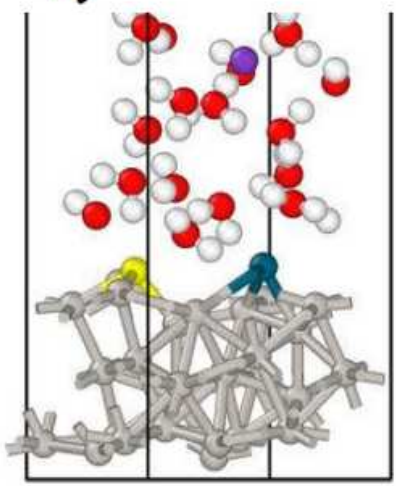

c)

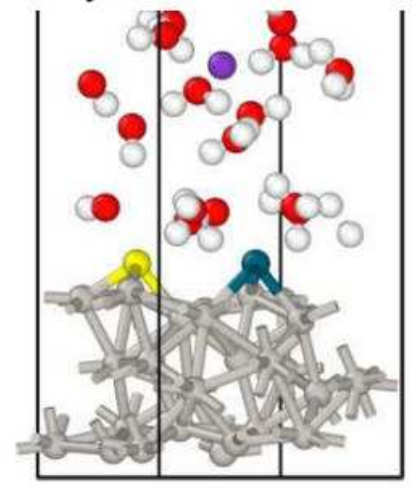

d)

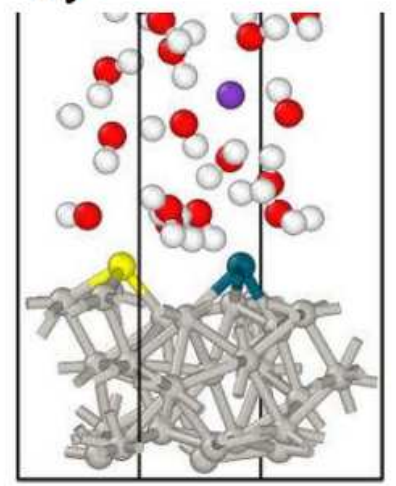

Figure 4

Snapshots of the time evolution of the Pd-Ru@Pt (111) slab shown at a) the initial configuration, b) 6,000 fs, c) 12,000 fs and d) 18,000 fs. Color code: Gray, green, yellow, white, red, and purple spheres represent $\mathrm{Pt}, \mathrm{Pd}, \mathrm{Ru}, \mathrm{H}, \mathrm{O}$, and K, respectively. 

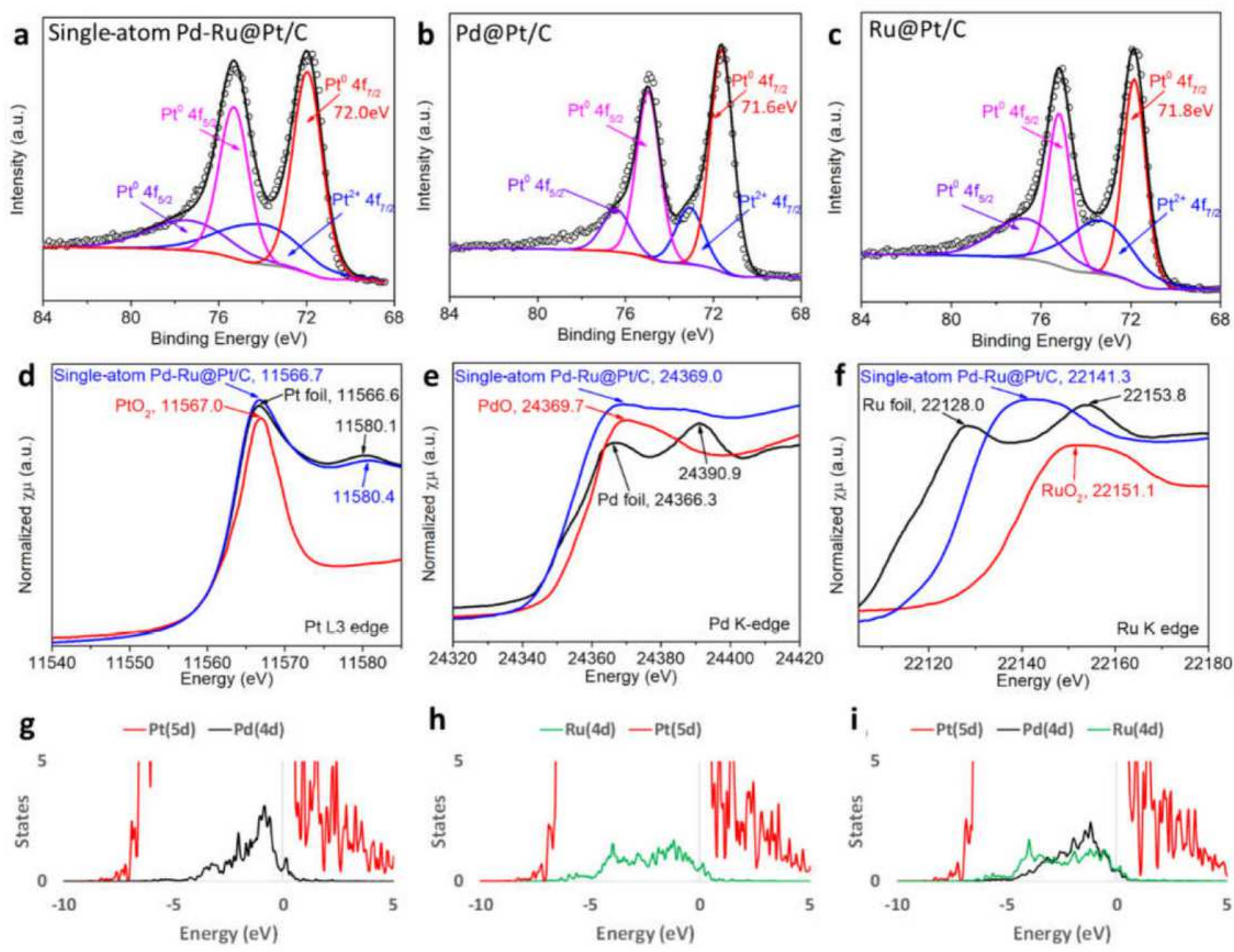

\section{Figure 5}

Electronic structure characterization. XPS pattern of Pt 4f for (a) single-atom Pd-Ru@Pt/C, (b) Pd@Pt/C, and (c) Ru@Pt/C. (d) Pt L3-edge, (e) Pd K-edge, and (f) Ru K edge Xray Absorption Near Edge Structure (XANES) spectra. XANES of metallic Pt and PtO2 are shown in (d) as references12. XANES of metallic Pd and PdO are shown in (e) as references13. XANES of metallic Ru and RuO2 are shown in ( $f$ ) as references14. Partial density of states (PDOS) for (g) Pd-doped system, (h) Ru-doped system, and (i) single-atom Pd-Ru@Pt (111) slab. 

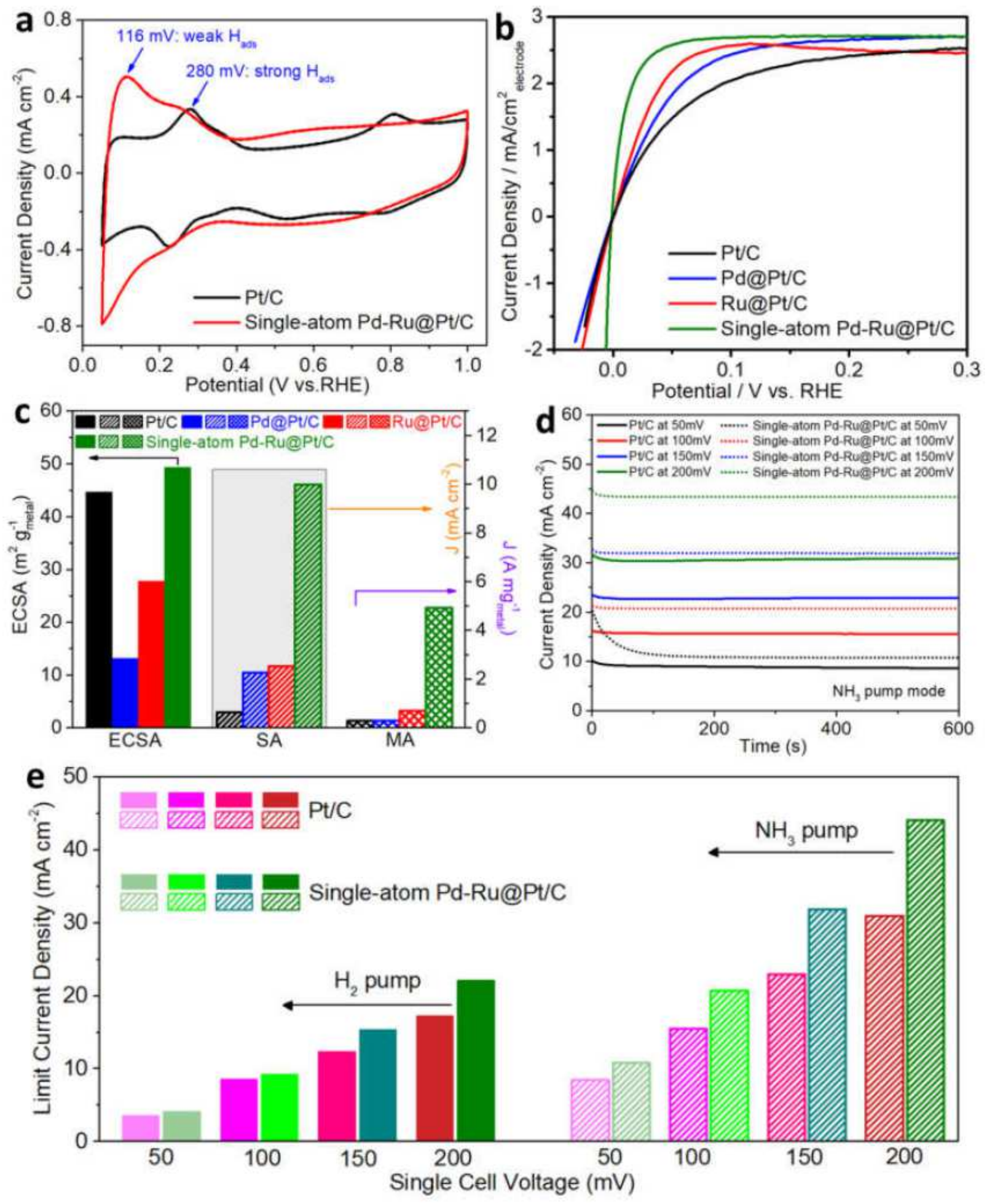

\section{Figure 6}

Electrochemical performance and mechanism of different catalysts. (a) CV curves of different catalysts. Test condition: 0.05 to $1.00 \mathrm{~V}$ vs. RHE, $50 \mathrm{mV} / \mathrm{s}$, N2-saturated $0.1 \mathrm{M} \mathrm{KOH}$. (b) HOR polarization curves of different catalysts. Test condition: -0.05 to $0.40 \mathrm{~V}$ vs. RHE, $10 \mathrm{mV} \mathrm{s}-1, \mathrm{H} 2$-saturated $0.1 \mathrm{M} \mathrm{KOH}, \mathrm{RDE}$ at 1600 rpm. (c) Comparison of ECSA (black arrow, left axis), SA (normalized by ECSA, orange arrow, right axis) and MA (normalized by Pt mass, purple arrow, right axis) for HER at $50 \mathrm{mV}$ vs. RHE for all tested 
catalysts. (d) Gibbs Free energy profiles for catalysts at equilibrium potential and $\mathrm{pH}=14$. (e) Comparison of limit current density of $\mathrm{Pt} / \mathrm{C}$ and single-atom $\mathrm{Pd}-\mathrm{Ru} @ \mathrm{Pt} / \mathrm{C}$ under $\mathrm{H} 2$ pump and $\mathrm{NH} 3$ pump mode in electrochemical cell. Test condition: Nafion 211 membrane, $5 \mathrm{~cm} 2$ electrode, $25^{\circ} \mathrm{C}, 34 \%$ relative humidity $(\mathrm{RH})$ for $\mathrm{H} 2-\mathrm{NH} 3$ mixture, 0.2 bar $\mathrm{H} 2-\mathrm{NH} 3$ mixture at flow rates of $50 \mathrm{~mL}$ min-1 of $\mathrm{H} 2$ and 100 $\mathrm{mL} \min -1$ of $\mathrm{NH} 3$.

\section{Supplementary Files}

This is a list of supplementary files associated with this preprint. Click to download.

- Supportinginformation.pdf 